\title{
INFORMATION, BILATERAL NEGOTIATIONS, AND WORKER RECRUITMENT
}

\author{
Arthur Schram, Jordi Brandts, and Klarita Gërxhani
}

July 2009

\begin{abstract}
This paper studies experimentally how firms choose between using a centralized market and bilateral negotiations to recruit new personnel. In the market firms interact with several workers but do not have information about workers' behavior in the past. In the bilateral negotiations firms negotiate bilaterally with prospective workers and learn about workers' performance in previous jobs. We show that the interaction between social preferences, the incompleteness of contracts and the existence of information about a worker's past performance provides an explanation for firms forgoing market opportunities and bilaterally negotiating with a worker. We observe that approximately $30 \%$ of all job contracts were bilaterally negotiated when these contracts are incomplete as opposed to only $10 \%$ when contracts were complete. The surplus from trade is higher when incomplete contracts can be bilaterally negotiated which can be attributed to the presence of information.
\end{abstract}

\section{Keywords}

Worker Recruitment, Labor Markets, Bilateral Negotiations, Indirect reciprocity, Experiments

\section{JEL Classification Codes}

C90, J30, J40

\section{Acknowledgements}

Financial support by the Spanish Ministerio de Educación y Ciencia and the Barcelona Economics Program of CREA is gratefully acknowledged. Remaining errors are ours.

\section{Authors}

\begin{tabular}{|c|c|c|}
\hline Arthur Schram & Jordi Brandts & Klarita Gërxhani \\
\hline CREED & Department of Business Economics & Faculty of Social and Behavioural \\
\hline Amsterdam School of Economics & U. Autònoma de Barcelona and & Science \& Amsterdam Institute for \\
\hline University of Amsterdam & Institut d’Anàlisi Econòmica, & Advanced Labour Studies \\
\hline Roetersstraat 11 & CSIC & University of Amsterdam \\
\hline 1018 WB Amsterdam & Campus UAB & Oudezijds Achterburgwal 185 \\
\hline The Netherlands & 08193 Bellaterra (Barcelona) & 1012 DK Amsterdam \\
\hline & Spain & the Netherlands \\
\hline phone $+31-20-525.4293$ & phone $+34-93-580.6612$ & phone $+31-20-525.4113$ \\
\hline fax $+31-20-525.5283$ & fax +34-93-580.1452 & fax: +31-20-525.3010 \\
\hline Schram@uva.nl & Jordi.Brandts@uab.es & k.gerxhani@uva.nl \\
\hline
\end{tabular}




\section{Introduction}

When firms are looking to hire new workers, they typically have incomplete information about the relevant characteristics of prospective candidates. Recruiting basically involves finding ways to uncover as much of this information as possible. In practice, firms recruit workers through fundamentally two broad channels. Centralized market institutions are one. In such markets, numerous firms and workers interact at the same time and a substantial part of the information about offers and trades is disseminated to market participants. In many countries, public or private employment agencies provide the services of such centralized exchanges. ${ }^{1}$ The other broad recruitment channel consists of informal networks of common acquaintances that facilitate the matching between the two sides of the labor market. In these networks contacts between firms and workers take place in a much more decentralized way.

The choice between recruitment channels involves a trade-off. If a firm decides to find a worker through an informal network, it gives up the transparency of the centralized market with respect to wages as well as the possibility of establishing contacts with a large number of workers. At the same time contacts in the informal network may be able to provide the firm with more accurate information about the prospective workers than what is available in the centralized markets.

Sociological research has long shown that for some types of jobs networks generate most job matches (Granovetter 1974, 1995; Corcoran et al. 1980; Holzer 1987; Boxman and Flap 1991; Montgomery 1991). This literature shows that jobs found via social networks are of higher quality, better paid and of higher occupational status than average (Lin et al. 1981; Lin et al. 2001; Flap and Volker 2004). Many economic studies use search and matching models to analyze recruitment behavior in the labor market. ${ }^{2}$ Some of these models account for the two types of channels (Barron and Bishop 1985; Montgomery 1991; van Ours and Ridder 1991, 1992; Gorter et al. 1993; Lindeboom et al. 1994; Chan 1996; Gorter and van Ommeren 1999; Russo et al. 2000; 2001; Behrenz 2001; Rogerson et al. 2005; Kugler 2003). A number of these studies provide support for the sociologists' findings and suggest that the use of informal channels is more efficient than other forms of recruitment, especially for key

\footnotetext{
${ }^{1}$ Recruitment through advertisment in newspapers or web sites also falls in this category (Rees, 1966).

2 Traditionally, most of the economic research on job matching has focused only on workers' searching behavior (Hicks 1932; Stigler 1961, 1962; Phelps 1968; Phelps 1970; McCall 1970; Mortensen 1970; Burdett and Mortensen 1980; Albrecht and Axell 1984; Pissarides 1990; Mortensen and Pissarides 1999; Bontemps et al. 2000). The strength of this literature lies in the explicit modeling of the costs and benefits related to searching for a job.
} 
positions in firms. However, recruitment through networks can also lead to inefficiencies because of mismatches between a worker's chosen occupation and her comparative productive advantage (Bentolila et al. 2004).

Potential workers may vary in productivity type. In that case, informal channels may reduce firms' information acquisition costs about such types and lead to more efficient hiring outcomes. Moreover, often contracts are necessarily incomplete (i.e., characterized by moral hazard). If this is the case, information that is not merely about (productivity) types of workers may be relevant to a firm. For example, a firm may want to know how trustworthy a worker has been in previous jobs. This aspect has been largely neglected in the economic search models described above. At the moment of recruiting new workers, social networks of various kinds are potential sources of this type of information. Such social networks are sometimes envisioned as information networks, as in Rees (1966) and Coleman (1988).

Hence, understanding the importance of information about previous performance as transmitted through social networks is important in improving our knowledge of the workings of the labor market as a whole (Marsden 2001). We present experimental data to this. Laboratory experiments provide an ideal environment to isolate the effect of information about a worker's trustworthiness in the recruitment process. In addition, the laboratory allows one to precisely control the information about the worker that is given to the firm. In our environment firms choose between two recruitment channels when hiring new workers. One of the channels is a centralized double auction market in which firms and workers bid and ask wages until a transaction is agreed upon. The other channel is an informal one in which firms and workers meet in bilateral negotiations. Here is where information comes in. When a firm is involved in a bilateral negotiation with a potential worker, we provide it with information about this worker's performance in previous jobs.

The relevance of this information may depend on the conditions under which recruitment takes place. To understand some of the ways in which the use of the recruitment channels emerges endogenously, we allow for variation in the environment along two dimensions. ${ }^{3}$ First, we vary the direction of market imbalance, i.e., whether labor is in excess demand or

\footnotetext{
${ }^{3}$ Endogenously chosen market institutions have been studied theoretically (Alós-Ferrer and Kirchsteiger, 2003; Neeman and Vulkan 2002; Rust and Hall 1993; Kugler 2003 presents a theoretical and field-data analysis) and experimentally (Kugler et al. 2004; Kirchsteiger et al. 2005; Tallroth 2003). Most of these studies show how both market and non-market institutions can be stable in the long run. In Neeman and Vulkan (2002) and Kugler et al. (2004), however, where buyers and sellers are heterogeneous and the quality of the traded good is fixed, buyers with high values and sellers with low costs move from bilateral negotiations to a centralized market which is more advantageous to them. Subsequently, buyers with low values and sellers with high costs will follow to be able to trade at all and bilateral trading will tend to disappear. Observe that this phenomenon has little to do with information transmission in bilateral negotiations.
} 
excess supply in the labor market as a whole. This treatment aims to capture the idea that the tightness of the labor market significantly impacts the way in which firms recruit their personnel (Russo et al. 2001). The second variation relates to the type of job that a firm is recruiting for. In many occupations workers have considerable discretion about their performance at a job (e.g., through the amount of effort they exert; Williamson 1981; Milgrom 1988; Baker 1992; Goldthorpe 2000; Eguchi 2005). For such jobs with incomplete contracts the performance history of prospective workers may be relevant information at the time of the recruitment decision. This information pertains directly to actual work-related behavior in the past and therefore it may indicate what effort to expect from a worker in the present. In contrast, if contracts are complete firms can largely control performance on the job, hence workers' performance histories are largely irrelevant and recruiting through informal channels may not offer any advantages.

Simple economic intuition might suggest that, in the presence of a transparent market, the existence of bilateral negotiations should not be expected to alter recruitment behavior. However, the important line of work initiated by Fehr et al. $(1993,1998)$ and continued by, among others, Hannan et al. (2002), Falk and Fehr (2003), Charness (2004), Falk and Kosfeld (2004), and Brandts and Charness (2004) has shown that, when contracts are incomplete, elements of trust and trustworthiness, fairness and reciprocity have a strong influence on the workings of the labor market. When contracts are incomplete, trustworthy workers are valuable. Firms may find reliable information about the trustworthiness of a worker being recruited through a social network.

In a related study, Brown et al. (2004) examine the emergence of fixed long-term partnerships between workers and firms under incomplete contracting. ${ }^{4}$ Firms are willing to invest in workers early on by offering high wages, and workers respond by working hard from the start. Firms then make private offers to the same workers in subsequent rounds, and an ongoing relationship arises based on mutual trust and reciprocity. The crucial difference between Brown et al. (2004) and our study is that we investigate the way in which the presence of information in bilateral negotiations influences how the recruitment of new workers comes about. In the labor market outside of the laboratory, this information about workers with whom they have no previous employment relationship is generated through informal networks of firms. By allowing for the possibility that a firm offers high wages to workers that worked hard elsewhere in the past, we are able to show that indirect reciprocity is

\footnotetext{
${ }^{4}$ In a subsequent working paper Brown et al. (2008) report additional evidence in this line. Moreover, Brown and Zehnder (2005) apply this framework to a credit market environment and find similar results.
} 
essential for initial recruitment (Engelmann and Fischbacher 2004, Bolton et al. 2004, Seinen and Schram 2006). In contrast, Brown et al. are interested in how direct reciprocity fosters an ongoing relationship between worker and firm where first time contacts are coincidental.

Our experimental results show that such information is important for recruitment when contracts are incomplete. Many firms recruit through bilateral negotiations, where wage and effort levels are higher than in the market. Consequently, the possibility of hiring through bilateral negotiations increases economic surplus. One source of the surplus gain is the direct reciprocation by the worker of the firm's trust. The starting point, however, is a firm offering a high wage in bilateral negotiations to a new worker who exerted high effort for other firms in the past. To conclude, our experimental design reveals what one misses if one thinks about the labor market purely in terms of centralized institutions.

\section{Design and Procedures}

The computerized experiment was run at the CREED laboratory of the University of Amsterdam in 8 sessions of approximately 90 minutes, with a total of 21 markets with 147 participants. Average earnings were $€ 24.99$, including a $€ 5$ show-up fee. The strategic environment is presented to participants without explicit reference to any labor market concepts. The situation is presented in terms of a market in which an abstract good is traded between buyers and sellers. However, given our focus on recruitment in the labor market, we will henceforth maintain the reference to 'firms' and 'workers' instead of buyers and sellers, respectively. ${ }^{5}$

The participants in the experiments interact during a total of 30 market rounds, preceded by three practice rounds; each subject has the constant role either of a firm or of a worker and can be involved in at most one trade per round. Trade can take place in two ways: through a centralized market institution or through bilateral (private) negotiations. There are 7 traders per market (depending on the treatment with either 5 firms and 2 workers, or vice versa) with at most two trades per market and round. The same 7 traders interact anonymously in a market throughout the 30 rounds. After the market closes the 'effort level' of each worker involved in a trade is determined. This affects the payoffs to firms and workers in a way to be discussed below.

\footnotetext{
${ }^{5}$ Here we follow the seminal papers in the area. Fehr et al. $(1993,1997,1998)$ all use instructions with a buyerseller frame in experiments which focus on labor market issues. We follow the authors of these studies in that, if anything, using the buyer-seller frame will tend to bias results against the emergence of issues of fairness, stable long-term relations, etc.
} 
Our main design consists of four separate treatments, varying along two dimensions and yielding a 2x2 factorial design. The first dimension consists in whether or not workers can choose their own effort levels. In what we call the incomplete contracts situation workers freely choose either a high or a low effort after having been hired by a firm. In our complete contracts treatment workers do not have this possibility and the firms set workers' effort levels; this represents firms' complete control in this case and allows us to keep things procedurally parallel. The second dimension along which our treatments differ is in whether there is excess supply (5 workers, 2 firms) or excess demand (2 workers, 5 firms) on the market. Table 1 summarizes our design and gives the number of markets we ran per treatment cell.

Table 1: Experimental Treatments

\begin{tabular}{|l|c|c|}
\hline & $\begin{array}{c}\text { Complete Contracts } \\
\text { (no moral hazard) }\end{array}$ & $\begin{array}{c}\text { Incomplete Contracts } \\
\text { (moral hazard) }\end{array}$ \\
\hline Excess supply: 5 workers, 2 firms & 5 markets, 30 rounds & 5 markets, 30 rounds \\
\hline Excess demand: 2 workers, 5 firms & 5 markets, 30 rounds & 6 markets, 30 rounds \\
\hline
\end{tabular}

In the first 10 rounds firms and workers interact only through a centralized market institution. This market is organized as a standard double auction (DA), in which both firms and workers are able to make public wage proposals at any time during a market period. To ensure anonymity across rounds, participants' positions on the monitor are randomly reallocated in every round. We chose the double auction, because it is usually considered to be the institution that best embodies the characteristics of well-functioning markets, where prices and transactions come about through an equilibrating process. Bids and asks in the double auction consist of an integer between 0 and 50, inclusive; these wage proposals are public. If a market wage proposal is accepted then a match is established. The transaction wage is denoted by $w_{D A}$. Subjects have 90 seconds to make trades. After two trades have been realized or 90 seconds have passed (whichever comes first), the market closes. Traders that have not entered a trade earn zero. For the cases with a trade agreement the worker's effort level $(e)$ is then determined. The two possible effort levels are 'high' $(e=1)$ and 'low' $(e=0)$ with resulting payoffs as explained below. After a worker's effort has been determined, this is communicated only to the firm and worker concerned. Neither knows the identity of those making or accepting offers, nor do they know the history -of wage or effort levels- of any of the other market participants.

A firm's payoff $\left(\pi_{f}\right)$ is equal to the revenue resulting from the worker's effort level, $r(e)$ minus the wage paid, with $r(1)=50$ and $r(0)=10$. A worker's payoff $\left(\pi_{l}\right)$ is equal to the wage 
received minus the cost of effort $c(e)$, with $c(1)=20$ and $c(0)=0$. Note that high effort maximizes the surplus from trade. Summarizing:

$$
\begin{aligned}
& \pi_{f}=r(e)-w_{D A} \\
& \pi_{l}=w_{D A}-c(e) .
\end{aligned}
$$

These initial 10 rounds establish a clear expectation about the wage level that arises in a centralized market. After the 10 market rounds, subjects receive new instructions in which the following situation was laid out for each of the new 20 rounds. At the beginning of each round firms have the opportunity to either enter the centralized market or propose bilateral negotiations $(\mathrm{BN})$. The centralized market works just like the one for the first 10 rounds. To enter bilateral negotiations, firms express a wish to negotiate. For every firm that indicates this wish, one worker is randomly selected. If there are more negotiation requests than workers, the firms to engage in negotiations are randomly selected. The selected workers are then asked whether they want to enter the bilateral negotiations. After all workers have reacted, the bilateral wage negotiations and the market open simultaneously. All firms and workers that have not been paired for bilateral negotiations enter the centralized market.

In the firm-worker pairs that are matched for bilateral negotiations each firm is informed about the number of times that the worker it is matched with chose low effort and high effort in previous rounds. ${ }^{6}$ This information includes those jobs in which the matching with a firm had taken place through the centralized market but excludes the decisions of the first 10 rounds (where there are no bilateral negotiations). Firms are not informed of wages earned previously by the worker. The main reason is that we think that this is the way in which information is exchanged amongst firms outside of the laboratory. For example, a typical letter of recommendation will provide information about whether the worker concerned is a hard worker but not about the wage this worker had been earning in the previous job. Finally, firms and workers do not learn the identity of their partners in a matching. We imposed this anonymity and the random matching procedure precisely because our focus is not on the formation or dynamics of bilateral relations, but on the impact of information on initial recruitment.

After a firm has seen the information about previous effort choices, it makes a bilateral wage offer to the worker it is matched with, which - like in the market - consists of an integer

\footnotetext{
${ }^{6}$ We do not model more in detail the micro-structure of information transmission in the network. Doing this here would complicate the experiment unnecessarily. Our representation captures what for us is the crux of the matter, namely that the network offers more information but fewer contacts. Boorman (1975) and CalvóArmengol (2004) present theoretical models of information transmission in job contact networks.
} 
between 0 and 50. ${ }^{7}$ Matched workers can then accept or reject the corresponding offer. We denote an accepted wage in the negotiations by $w_{B N}$. Those involved in the bilateral wage negotiations can at all times observe the bids and the trades made in the public market. In contrast, participants in the market are not informed about what is happening in the negotiations; this again represents the transparency of a market and the lack of it in bilateral negotiations. The firms whose offers are rejected and the workers that have rejected immediately enter the centralized market, joining the firms and workers that have not engaged in bilateral negotiations. Each round again lasts for 90 seconds. $^{8}$ After the trades have been determined, the effort decision for the workers involved is made. This yields payoffs as in eq. (1), where $w_{D A}$ is replaced by $w_{B N}$ for trades in the bilateral negotiations. ${ }^{9}$

A summary of the experimental design is given in Figure 1. See Appendix A for a translation of the instructions.

\section{Hypotheses}

In this section we present specific hypotheses about wages, effort levels and the use of the two recruitment channels. The main question is how the option of using bilateral negotiations will affect wages, effort, and -as a consequence- realized surplus from trade. In section 3.1 we derive a benchmark for our predictions by presenting the implications of the interaction of purely individualistic agents. The expected behavior of purely inequity-averse participants is derived in section 3.2, which also summarizes what previous experimental literature suggests will occur in our environment. On the basis of all this we formulate alternative hypotheses.

\subsection{Individualistic Preferences}

Given common knowledge of a finite horizon and self-interest, the theoretical predictions are straightforward. High effort will always be chosen when contracts are complete and low effort when they are incomplete, independent of whether the trade is made in the market or through bilateral negotiations. Wages depend on whether effort is low or high and on whether the market is favorable to firms or workers. Under excess demand for labor, wages are such that all the surplus goes to the workers and the opposite is predicted under excess supply. All the effort and wage predictions for our parameters for any round are shown in table 2.

\footnotetext{
${ }^{7}$ Note that the initiative is on firms' side in the bilateral negotiations, in the sense that they decide whether to offer negotiations in the first place and also make the wage offers. This asymmetry reflects the basic power relations present in the labor market.

${ }^{8}$ Firms may delay making an offer to make it difficult for workers to reject and still get into the trading in the public market. However, in the experiments very few firms substantially delayed making offers.
} 
Figure 1: Experimental Design

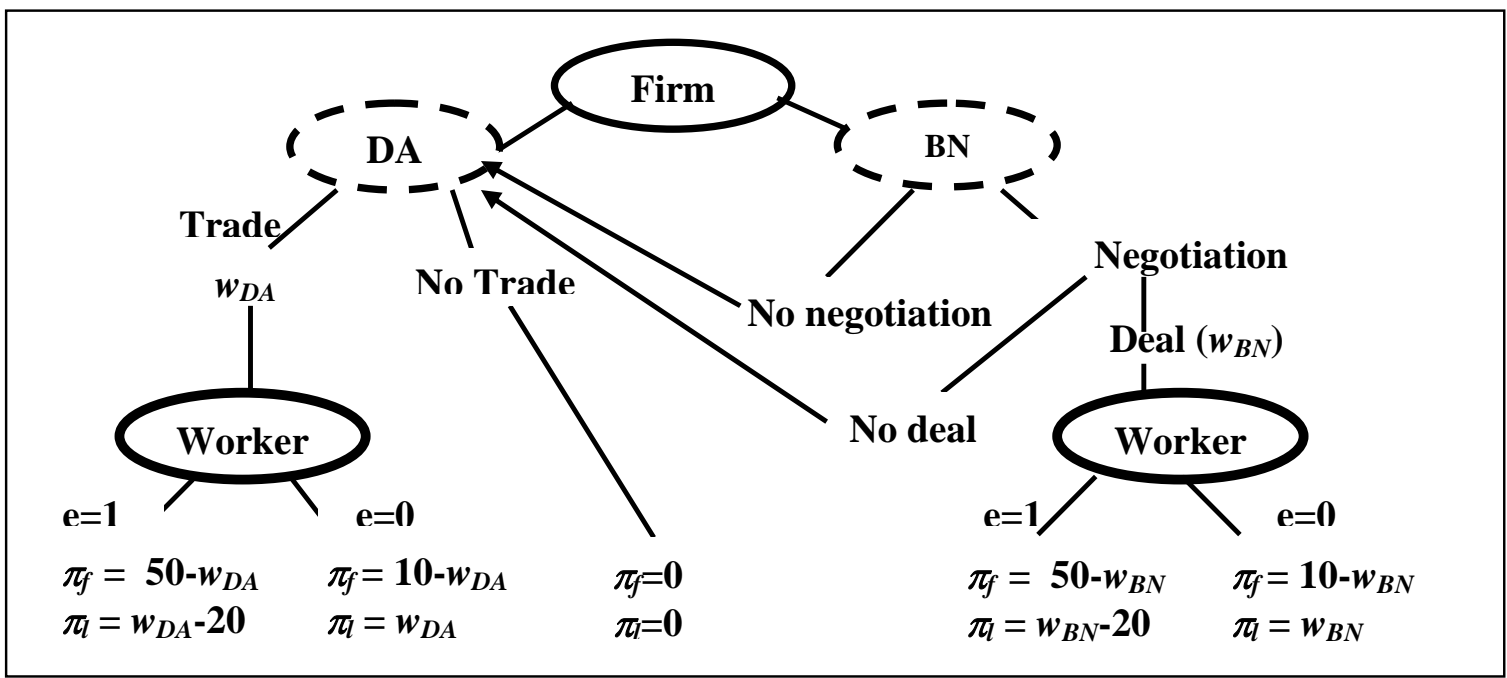

Notes. DA=Double Auction; BN=Bilateral Negotiations; In BN the firm first offers bilateral negotiations to one worker. If this is rejected, the firm and worker participate in DA. The same holds if the offer to negotiate is accepted but the wage offer in $\mathrm{BN}$ is rejected by the worker.

Table 2: Equilibrium Predictions, Individualistic Preferences

\begin{tabular}{||l|l|c|c|c|c||}
\hline \multicolumn{2}{|c|}{} & \multicolumn{2}{|c|}{ Complete Contracts } & \multicolumn{2}{c||}{ Incomplete Contracts } \\
\cline { 3 - 6 } \multicolumn{2}{|c|}{} & $\mathrm{DA}$ & $\mathrm{BN}$ & $\mathrm{DA}$ & $\mathrm{BN}$ \\
\hline \multirow{2}{*}{ Effort } & $e=1$ & $e=1$ & $e=0$ & $e=0$ \\
\hline \multirow{2}{*}{ Wage } & Excess Demand & $w_{D A}=50$ & $w_{B N}=50$ & $w_{D A}=10$ & $w_{B N}=10$ \\
\cline { 2 - 6 } & Excess Supply & $w_{D A}=20$ & $w_{B N}=20$ & $w_{D A}=0$ & $w_{B N}=0$ \\
\hline
\end{tabular}

Notes: Numbers denote predictions for the treatment cells distinguished. Predictions hold for all rounds. $D A=$ double auction market; $B N=$ bilateral negotiations.

The most important qualitative implications of what is shown in table 2 - which below will give rise to our null hypotheses - are the following:

(i) Effort is higher under complete than under incomplete contracting.

(ii) In all treatments, effort is the same for DA and for $B N$.

(iii) Wages are higher under complete than under incomplete contracting.

(iv) Wages are higher under excess demand than under excess supply.

(v) In all treatments wages in the DA and those agreed upon in the BN are the same.

(vi) In all treatments, subjects are indifferent between trading via the $D A$ and the $B N$.

Item (i) of the null hypothesis simply reflects the fact that effort will be determined following the interests of whoever controls it and (ii) states that this will be unaffected by the recruitment channel. Item (iii) is a consequence of (i). In the complete contracting case workers know that firms will impose high effort and, therefore, they need to be offered sufficiently high wages to accept a trade. For incomplete contracting firms know that workers will choose low effort and, hence, firms will only be willing to offer low wages and workers will accept them. Item (iv) just responds to a fundamental feature of the workings of markets,

\footnotetext{
${ }^{9}$ As noted by an anonymous referee, our design assumes that recruiting costs are equal in both channels. We see this as an appropriate benchmark for our analysis. One can think of reasons why costs may be higher in DA than in BN (e.g., because
} 
which has been observed in numerous experiments (see Holt et al. 1986 and Davis et al. 1993), though previous experimental evidence suggests that we should not expect contracts exactly at boundary wages (which yield zero profit to one of the partners), but only close to them. Item (v) is quite crucial and is directly related to (ii). Effort will not differ across recruitment channels and, therefore, wages will not differ either. Finally, item (vi) formulates that if both sides have nothing to gain from trading through either of the channels, then they will be indifferent between them.

\subsection{Other-regarding Value Orientations}

In many experimental labor environments the predictions based on individualistic preferences have not fared well. A substantial fraction of participants exhibit behavior that reveals preferences that include a concern for others' well-being. Over the past decade numerous studies have appeared trying to model these other-regarding preferences (for examples, see Fehr and Schmidt 1999; Bolton and Ockenfels 2000; Charness and Rabin 2002; or Cox et al. 2007). Camerer (2003, p. 472) advises using the inequity-aversion model of Fehr and Schmidt (1999), (henceforth FS99), when studying wage-setting and bargaining. In considering the effects of other-regarding value orientations we, therefore, start with the implications for equilibrium behavior of this kind of inequity-aversion. As in any of these models, these implications depend on the extent of inequity aversion in the population, for which (for obvious reasons) we need an out-of-sample estimate. We find an estimate in FS99, where they determine the proportion of inequity-averse agents based on accumulated evidence on the ultimatum game. FS99 argue that this can account for the regularities in a wide range of games.

This subsection starts with a heuristic presentation of the main implications of the inequity aversion model with the FS99 estimated. After that we present a wider view of the impact of other-regarding value orientations, including a discussion of the consequences of alternative estimates of the extent of inequity aversion. In Appendix B we present a formal analysis of the experimental setting and derive predictions for the parameters of our experiment (Schram et al. 2007 derive predictions for general parameters settings).

To start, consider inequity-aversion with complete contracts. Here high effort will always be chosen, since it yields the highest surplus and firms will be better off in the high surplus case. In the DA, competition will crowd out inequity concerns (FS99) and the extreme wage predictions for individualistic preferences carry over. In BN, however, inequity-aversion may affect realized wages if firms and workers consider their negotiation partner to be the only

of advertisement and screening costs), but the reverse may hold just as well (for example, because negotiations take longer). 
relevant reference agent. This is the assumption made in FS99 and Brown et al. (2004); we think that it is plausible and adopt it here. Since disadvantageous inequity is evaluated more negatively than advantageous inequity, the short side of the market (which ends up with all of the surplus in the absence of inequity-aversion) will in this case end up with more than half of the surplus from trade, but not necessarily with the whole pie. The FS99 equilibrium predictions for complete contracts are shown in the third and fourth columns of table 3.

Next we discuss incomplete contracts. To see whether a 'gift exchange' type of behavior (a situation where a firm offers a high wage, which is 'reciprocated' by the worker choosing high effort; $c f$. Fehr et al. 1998) will emerge in equilibrium, consider first the workers' situation. Inequity-averse workers may be willing to provide high effort in response to a sufficiently high wage, because they dislike the large inequity that would be caused by exploiting the high wage through a low effort choice. Appendix B shows that for our parameters wages need to be higher than a reservation wage of 30 for this to occur. If firms were certain that workers are inequity-averse they would be willing to offer such a high wage, knowing that any worker would refrain from exploiting the offer. More specifically, it follows from appendix B (table B1) that in this complete information scenario wage offers in the intervals $[0,5]$ and $[30,35]$ can be supported in equilibrium when there is excess supply while this holds for wages in the intervals $[5,10]$ and $[35,50]$ with excess demand.

In our experiment, firms cannot recognize whether particular workers are inequity-averse. They can only base their decisions on distributional assumptions. If sufficient workers are inequity-averse, the profit firms make when dealing with these workers compensates for the losses when being exploited by an inequity-neutral worker. Moreover, the existence of an information network through which firms receive information about past choices of a worker (which is revealed to the firm in $\mathrm{BN}$ ) introduces the possibility of reputation building. In the repeated game, firms may form beliefs about the inequity-aversion of a worker based on previous effort choices by that worker. Depending on the assumption about the proportion of inequity-averse workers, in the 20 round game a plethora of equilibria may result. The appendix shows, however, that the distribution of inequity aversion estimated by FS99 implies that there is no equilibrium where inequity-neutral workers provide high effort in early rounds in order to appear inequity-averse and obtain high wage offers in subsequent rounds. Moreover, the 'separating' situation where inequity-neutral workers receive low wages and offer low effort whereas inequity-averse workers choose high effort in response to high wages is not an equilibrium either. The case where all wage offers are low and are met 
with low effort is a ('pooling') equilibrium, however. The predictions corresponding to this equilibrium are the ones shown in the incomplete contracts columns of table 3.

Table 3: Equilibrium Predictions, Inequity-averse Preferences

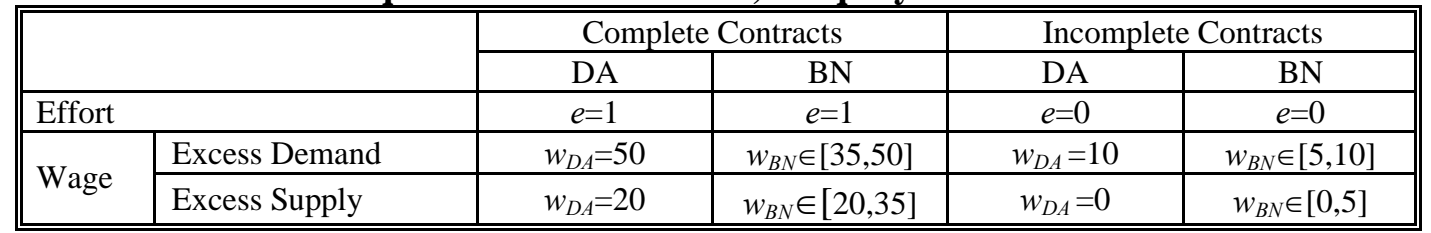

Notes: Numbers denote predicted wages for the treatment cells distinguished. DA=double auction market; $\mathrm{BN}=$ bilateral negotiations.

The equilibrium predictions shown in the incomplete contracts columns of table 3 posit no gift exchange. Hence, the occurrence of other-regarding preferences is not a sufficient condition to create a difference between trading in the DA and BN. Indeed, even for the outof-sample distribution of preferences that we used, no gift exchange will occur in equilibrium.

Yet, we are dealing with an environment in which simple intuition based on a variety of results from previous experimental studies suggests gift exchange will emerge. Of course, one way to create an equilibrium with gift exchange is to alter the assumed distribution of inequity-aversion. For their market with repeated interaction, Brown et al. (2004) show that a different assumption can yield equilibria with substantial gift exchange. In our case, this would inply a pooling equilibrium where all workers choose high effort in DA and BN until round 27 and only inequity-averse workers would maintain this until the end (cf. Appendix B). Only in the last three rounds does this predict a difference between DA and BN. Hence, simply assuming an alternative distribution of preferences will not yield a prediction of distinct behavior in DA and BN across rounds. In fact, our equilibrium is quite robust to the assumed distribution. Though some probability between 0.4 and 1 that the worker is inequityaverse will be sufficient to create the pooling equilibrium described, even a probability of 0.6 (as opposed to the 0.4 estimated in FS99) is insufficient to do so. Because we do not observe pooling in our data, we continue by considering other factors that may be relevant.

We also need to consider the regularities observed in numerous laboratory studies on labor markets. Previous studies all deal with the stand-alone DA. The seminal work on the DA case with incomplete contracts and excess supply of labor is by Fehr et al. (1993). ${ }^{10}$ It has been observed in the context of numerous design variations that firms pay wages substantially above the minimum and workers often choose effort above the lowest level. We should

\footnotetext{
${ }^{10}$ There is little difference between behavior in a one-sided and double auction (Fehr and Falk 1999).
} 
therefore expect to see similar behavior here. ${ }^{11}$ In our setting this translates into a prediction of firms paying wages above 30 and workers frequently choosing the high effort level. Wages will leave the larger part of the surplus with the short side of the market, but in a less extreme way than when firms control effort because of the gift exchange taking place with incomplete contracts. Note that this conclusion holds for the DA, irrespective of the possibility of engaging in $\mathrm{BN}$.

Now compare BN and DA for incomplete contracts. Given the occurrence of gift exchange in previous studies, it seems hard to believe that providing firms with information about the past effort choices will not affect outcomes. In a different setting, Seinen and Schram (2006) show that indirect reciprocity (rewarding someone for being kind to unkown third parties) can easily be generated in the laboratory by providing subjects with information about their partner's past choices. In our setting this suggests that the higher the proportion of previous high effort choices, the higher wage offers should be expected to be. ${ }^{12}$ For the equilibrium shown in table 3 , high wage offers would be out of equilibrium. However, if some high wages are offered initially in BN then these offers are more likely to be accepted than low offers. Low offers are more likely to be rejected possibly due to workers attempting to have better luck after switching to the DA. Consequently, the set of accepted BN offers will be a biased subset of all BN offers. We should therefore expect accepted wage offers to be higher in BN than in DA, where competitive forces drive out high offers more quickly. On average effort levels should also be expected to be higher in the BN than in the DA, since at least some of the workers will respond positively to higher wages.

These observations allow us to formulate qualitative implications of other-regarding value orientations. We capture them in six predictions, parallel to the case of selfish preferences.

(i) Effort is higher under complete than under incomplete contracting.

(ii) For both treatments with complete contracts, effort is the same for DA and BN. For both treatments with incomplete contracts, effort will be higher for BN than for DA.

(iii) Wages are higher under complete than under incomplete contracting.

(iv) Wages are higher under excess demand than under excess supply.

(v) Wages are higher in $B N$ than in $D A$.

(vi) The proportion of trade through $B N$ will be higher with incomplete contracts than with complete contracts.

\footnotetext{
${ }^{11}$ See Brandts and Charness (2004) for evidence that gift exchange occurs in completely parallel excess demand and supply conditions.

${ }^{12}$ Of course, there are differences in comparison to the standard indirect reciprocity setting. For example, in our setting one of the players, the firm, is not motivated by any reputational concerns. Moreover, the response by workers to a wage offer is a direct response, not indirect. However, the initial wage offer by the firm in bilateral negotiations may partly be determined by indirect reciprocity, in which case the firm would reward high effort choices the worker made for other firms in the past.
} 
Items (i), (iii), (iv) and the first part of (ii) are the same as those for individualistic preferences, so that we will not propose any formal hypotheses for them. The simple interpretation of this absence of differences is that, in our context, the existence of other-regarding value orientations does not affect fundamental economic forces. The remaining items predict a difference between behavior in DA and BN. While gift exchange may occur in DA (as in previous studies), higher wages and more high effort choices (ergo, higher trade surplus) ${ }^{13}$ are predicted for BN. In short, we predict that some traders will choose to trade outside of the market and that, contrary to basic economic intuition about the advantages of trading through markets, this will cause an increase in realized surplus.

This prediction can be more formally captured by deriving the hypotheses tests from the second part of item (ii) and of items (v) and (vi). The null hypotheses stem from the first set of six predictions -shown in section 3.1-corresponding to individualistic preferences, whereas the alternative hypotheses come from the list of this section. From (ii), we have:

$$
\mathrm{H}_{0}: e_{B N}(I C)=e_{D A}(I C)
$$

vs. $\mathrm{H}_{1}: e_{B N}(I C)>e_{D A}(I C)$,

where $I C$ denotes the treatment with incomplete contracts. Next, item (v) gives:

$$
\mathrm{H}_{0}: w_{B N}(I C)=w_{D A}(I C)
$$

vs. $\mathrm{H}_{2}: w_{B N}(I C)>w_{D A}(I C)$.

Finally, (vi) gives the formal hypothesis:

$$
\mathrm{H}_{0}: \tau_{B N}(I C)=\tau_{B N}(C C)
$$

vs. $\mathrm{H}_{3}: \tau_{B N}(I C)>\tau_{B N}(C C)$,

where $\tau_{\mathrm{BN}}$ denotes the fraction of trades through $\mathrm{BN}$ and $C C$ refers to complete contracts.

A different matter is the surplus realized from trade. Note that this is higher in case of a high effort (30) than with low effort (10). When contracts are incomplete high surplus is more likely to be observed in BN than in DA (item ii). Hence, we predict higher surplus in BN.

(vii) With incomplete contracts, realized surplus is higher in bilateral negotiations than in double auctions.

Formally, we test:

$$
\mathrm{H}_{0}: \pi_{f}(B N, I C)+\pi_{l}(B N, I C)=\pi_{f}(D A, I C)+\pi_{l}(D A, I C)
$$

vs. $\mathrm{H}_{4}: \pi_{f}(B N, I C)+\pi_{l}(B N, I C)>\pi_{f}(D A, I C)+\pi_{l}(D A, I C)$.

Finally, though we started from the FS99 model (eq. B1 in Appendix 2) as our benchmark regarding preferences in our experiment, we realize that both direct and indirect reciprocity

\footnotetext{
${ }^{13}$ Throughout this paper we will avoid using the term 'efficiency' when discussing trade surplus in order not to get caught up in social welfare considerations caused by non-selfish individual preferences.
} 
resulting from other motivations than inequity-aversion may affect behavior. For our experiments, we can define reciprocity as a positive response to trading partner's choice(s). For the firm, this reciprocity can only be indirect: it can reward with a high wage previous high effort choices the worker made for other firms. Note that this can only occur in BN. For the worker, this reciprocity can only be direct. It can reward a high wage (in either DA or BN) by choosing high effort. As a consequence, if reciprocity affects our comparative static hypotheses on top of the effect caused by inequity aversion, it reinforces the predictions discussed above. Therefore, the effects of reciprocity are covered by $\mathrm{H}_{1}-\mathrm{H}_{4}$.

\section{Results}

We start with a general overview of some key statistics. This is followed by a comparison of behavior across treatments, considering channel choice, wage levels, effort choices, and trade surplus. Then, we test whether it is actually the information given in bilateral negotiations that is driving our results. Where applicable, we include formal tests of the hypotheses derived in section 3. These are summarized in the final subsection. Unless stated otherwise, tests are either (two-sided) Mann-Whitney (for independent samples) or Wilcoxon (paired samples) tests using market averages across rounds as units of observation.

\subsection{General Overview}

We have data from 21 groups involved in 30 rounds each. Table 4 summarizes key statistics.

\section{Table 4: Key Statistics}

\begin{tabular}{|c|c|c|c|c|c|c|c|c|c|c|}
\hline & & & $\begin{array}{c}\% \text { of } \\
\text { possible } \\
\text { trades }\end{array}$ & $\begin{array}{c}\% \\
\text { trades in } \\
\text { BN }\end{array}$ & $\begin{array}{c}\text { Average } \\
\text { DA } \\
\text { wage }\end{array}$ & $\begin{array}{c}\text { Average } \\
\text { BN } \\
\text { offer }\end{array}$ & $\begin{array}{c}\text { Accep- } \\
\text { tance } \\
\text { rate } \mathrm{BN}\end{array}$ & $\begin{array}{c}\text { Average } \\
\text { BN } \\
\text { wage }\end{array}$ & $\begin{array}{c}\text { \% high } \\
\text { effort } \\
\text { DA }\end{array}$ & $\begin{array}{c}\text { \% high } \\
\text { effort } \\
\text { BN }\end{array}$ \\
\hline \multirow{4}{*}{$\begin{array}{l}\text { Excess } \\
\text { supply }\end{array}$} & \multirow{2}{*}{$\mathrm{CC}$} & R1-10 & 100 & -- & 21.0 & -- & -- & -- & 96.0 & -- \\
\hline & & R11-30 & 99.5 & 8.5 & 20.8 & 21.7 & 0.43 & 23.4 & 97.3 & 82.4 \\
\hline & \multirow{2}{*}{ IC } & R1-10 & 96.0 & -- & 15.7 & -- & -- & -- & 26.0 & -- \\
\hline & & R11-30 & 96.5 & 28.5 & 18.3 & 17.5 & 0.63 & 25.9 & 39.1 & 49.1 \\
\hline \multirow{4}{*}{$\begin{array}{l}\text { Excess } \\
\text { demand }\end{array}$} & \multirow{2}{*}{ CC } & R1-10 & 100 & -- & 46.2 & -- & -- & -- & 98.0 & -- \\
\hline & & R11-30 & 97.5 & 10.8 & 46.3 & 36.9 & 0.25 & 40.0 & 100 & 100 \\
\hline & \multirow{2}{*}{ IC } & R1-10 & 95.0 & -- & 27.4 & -- & -- & -- & 38.6 & -- \\
\hline & & R11-30 & 90.4 & 30.9 & 28.3 & 26.1 & 0.47 & 34.2 & 48.0 & 76.1 \\
\hline
\end{tabular}

Notes. IC= incomplete contracts; $C C=$ complete contracts. $R 1-10$ refers to first 10 rounds (without bilateral negotiations); $R 11-30$ refers to rounds $11-30 . \%$ of possible trades is number of realized trades as percentage of possible trades. \% of trades in $B N$ is number of bilateral deals as percentage of realized trades. Average DA wage $=$ average wage realized in the double auction; Average $B N$ offer= average offer by firms in $\mathrm{BN}$; Acceptance ratet $B N=$ fraction of $\mathrm{BN}$ wage offers accepted by workers; Average $B N$ wage $=$ average wage in bilateral deals. \% high effort $D A=$ number of high effort choices after double action trade as percentage of trades in double auction; \% high effort $B N=$ number of high effort choices after bilateral deal as percentage of bilateral deals.

In aggregate we observed 1214 trades out of a possible 1260 (two per market), indicating that almost all potential trades (96.3\%) were realized. Approximately 30\% of the trades were 
made through $\mathrm{BN}$ when contracts were incomplete but only around $10 \%$ when contracts were complete. A first thing to notice about wages is that the available BN option does not affect the DA: DA wages did not differ much between the first 10 rounds and rounds 11-30. Moreover, wage offers in BN are higher when labor is scarce, but they are not high enough, because fewer offers are accepted. Nevertheless, wages appear to be higher in BN than in DA when contracts are incomplete but not necessarily so for complete contracts. As for effort, almost all firms chose high effort in the complete contracts case. ${ }^{14}$ With incomplete contracts, there appears to be a clear ranking. The lowest percentage of high effort choices is observed in DA when there is no $\mathrm{BN}$ alternative while high effort is chosen most frequently after a bilateral deal. The percentage of high effort choices in DA in rounds $11-30$ is somewhere in between. ${ }^{15}$

To get a further impression of our data, figure 2 shows scatter plots of all realized trades. Together with table 4, this gives rise to the following observations. First, market imbalance matters. With excess supply, wages tend to be between 0 and 5 or 20 and 35 whereas excess demand yields wages between 5 and 10 or 35 and 50. This means that the short side of the market manages to get at least half of the surplus from trade. Second, incomplete contracts lead to more wage volatility and to wages that are closer to the equal split level of 35 . Third, both DA trades and BN trades occur. From table 4, we know that wages are higher in $\mathrm{BN}$, though this is hard to discern in the graph. Finally, there may be some adaptation in the first few rounds, but after round 5 the results remain remarkably constant. In particular, there is no obvious effect on DA of introducing BN in round 11 (as observed in table 4).

\subsection{Channel Choice}

We first consider the process of choosing bilateral negotiations. Recall that firms could start by offering $\mathrm{BN}$ to some unknown worker. The number of firms offering $\mathrm{BN}$ varied strongly across treatments. In line with intuition, fewer firms were willing to forgo the market opportunities when there was excess supply (32.3\%) than with excess demand (81.8\%). For workers, the effect is reversed. When offered the possibility, $99.5 \%$ of the workers seized the opportunity to enter $\mathrm{BN}$ in case of excess supply, whereas $50.4 \%$ of the workers were willing to negotiate when there was excess demand. ${ }^{16}$ Hence, the long side of the market is almost

\footnotetext{
14 The relatively low percentage (82.4\%) in $\mathrm{BN}$ with excess supply can be attributed to a low number of observations (17; 14 of which where followed by a high quality choice).

15 The observed $39.1 \%$ of high effort choices in DA for the excess supply scenario with incomplete contracts reinforces the typical gift exchange observed in many previous experiments ( $c f$. section 3 for references).

${ }^{16}$ In the excess supply treatment with moral hazard, there is a slight tendency for workers who previously chose high effort more often to enter negotiations more often. Workers who previously chose high effort in less than
} 
Figure 2: Trades

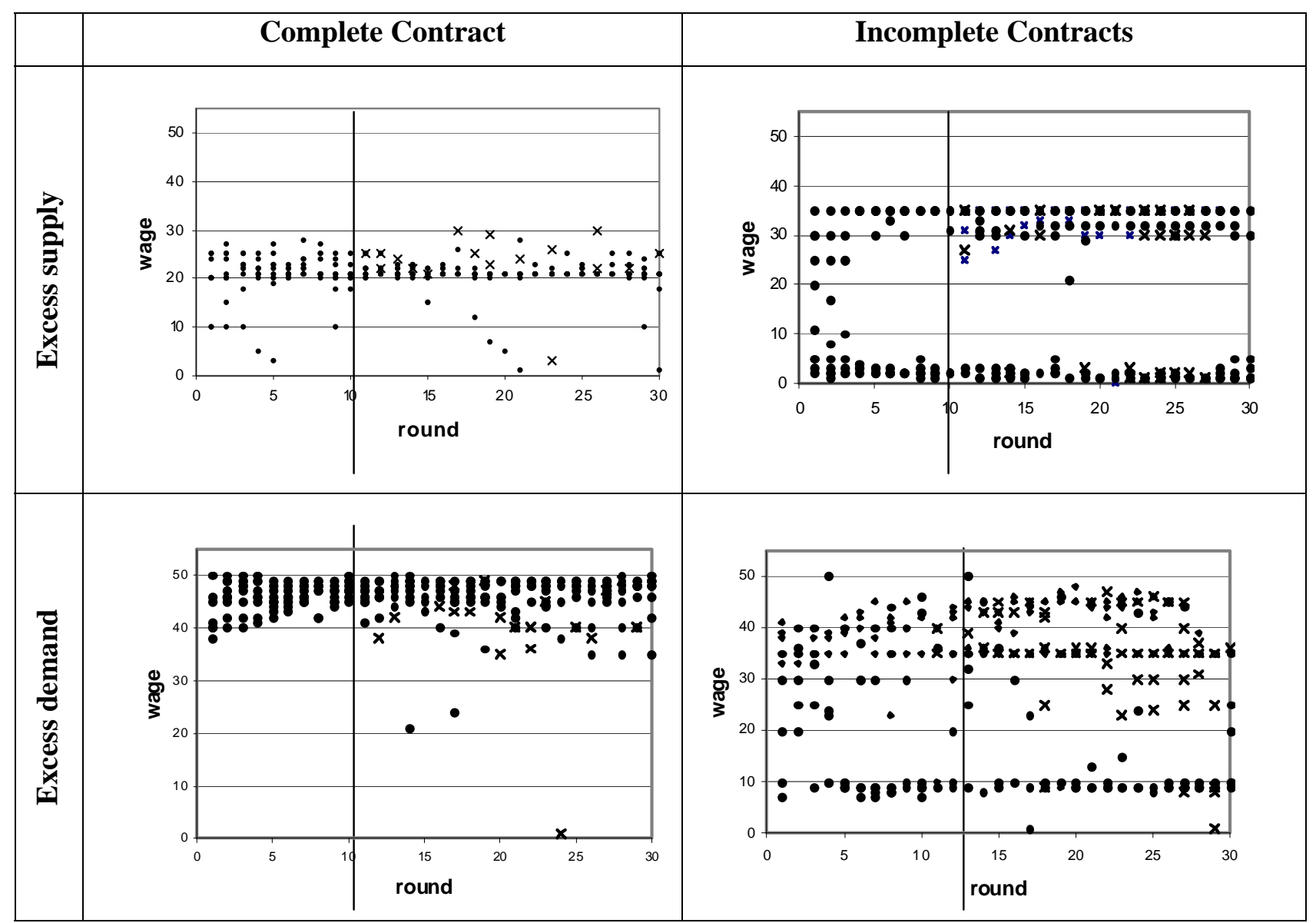

Notes. Dots indicate for every round (horizontal axes) all trades in DA (at the prices indicated on the vertical axes) and crosses indicate trades in the BN. In the first 10 rounds (separated by a vertical line) only DA trades were possible. Depending on the treatment, either 10 or 12 trades per round were possible (two for each market; $c f$. table 1 ). Multiple observations at the same point are indicated by a single dot or cross.

unanimously willing to bypass the DA. More surprisingly, the fraction of the short side that is willing to do so is also substantial. As for the homogeneity in firm choices, basically all firms suggested negotiations in all rounds, when there was excess demand. With excess supply but no moral hazard, firms rarely offered negotiations. There was quite some heterogeneity in firms' decisions to enter BN when there was excess supply and moral hazard, however. For this treatment we have data for 10 buyers (5 markets). Of these, three chose to go to the $\mathrm{BN}$ in 20 out of 20 rounds while one never does so. The remaining six are dispersed in between.

The interaction of firms' and workers' channel choices leads to the distinct levels of bilateral negotiations across treatments observed in table 4. More trades are bilateral in the

$50 \%$ of the time respond positively to invitations to negotiate in $48 \%$ of the time. Those who chose high effort in more than $50 \%$ of the cases respond positively $62.1 \%$ of the time. 
incomplete contract cases than for complete contracts. ${ }^{17}$ The market condition does not appear to affect the fraction of trades through BN. Neither for incomplete, nor for complete contracts does a systematic difference occur between excess demand and excess supply. To test $H_{3}$ $\left(\tau_{B N}(I C)>\tau_{B N}(C C)\right)$, we can therefore pool the data across market conditions. This gives 10 observations (average fractions across 20 markets) for complete contracts and 11 for incomplete contracts. The difference is statistically significant at the $1 \%$-level. Thus, we reject the null hypothesis derived assuming (common knowledge of) selfish preferences in favor of the alternative described by $H_{3}{ }^{18}$

\subsection{Wage Levels}

Wages may be affected by expected effort levels as well as by market imbalance and the channel chosen for the transaction. Because high effort is virtually always chosen when contracts are complete whereas many instances of low effort are observed with incomplete contracts, figure 3 shows the development of wages separately for these two treatments. To smooth out short-term volatility, the figures show 3-period moving averages.

Figure 3: Average Wages

\section{A: Complete Contracts}

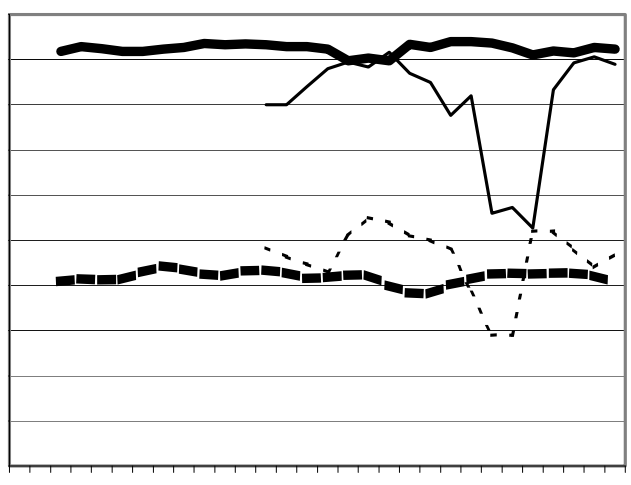

$\begin{array}{lllllllllllllll}1 & 3 & 5 & 7 & 9 & 11 & 13 & 15 & 17 & 19 & 21 & 23 & 25 & 27 & 29\end{array}$

\section{B: Incomplete Contracts}

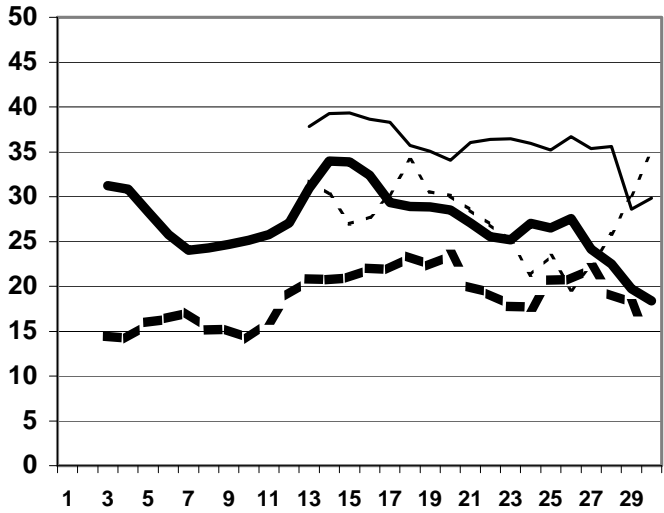

Notes. 3-round moving averages of observed wages are shown for complete (left panel) and incomplete contracts (right panel). Dashed lines show wages for excess supply and solid line reflect excess demand. Thick lines show wages for trades in DA and thin lines show BN wages. The sharp decreases in average $\mathrm{BN}$ wages during rounds 23-27 shown in the left panel are due to the fact that there are very few observations per round.

\footnotetext{
${ }^{17}$ A round-by-round analysis gives no evidence of a trend across rounds, though there is some indication that fewer trades are made bilaterally in the final two rounds. The numbers are too low to run any statistical analysis, however.

${ }^{18}$ With excess demand, firms may be entering BN to increase the possibility of engaging in a trade and this may cause a confound with other reasons to do so. With excess supply, firms are more or less assured of a trade in either channel. The fact that the fraction of bilateral trades is basically the same for the two market conditions (conditional on moral hazard) is an indication that the probability of trading is not a major motivation in the channel choice.
} 
We start by comparing wages in incomplete and complete contracts. Recall that both predictions derived from selfish preferences and those based on inequity-aversion are that wages will be higher in the latter case. Statistically, this is supported for DA wages ( $p=0.036$ ) but not for $\mathrm{BN}$ wages ( $p=0.132$; recall that these results and those of all pair wise test results reported below, are based on the independent average observations from the 21 markets). Distinguishing between excess supply and excess demand shows marked differences, however. When there is excess demand, both DA wages $(p=0.004)$ and BN wages $(p=0.052)$ are statistically significantly higher with complete contracts, whereas equal wages in complete and incomplete contracts cannot be rejected in either channel when there is excess supply ( $p=0.841, p=0.690$, respectively).

Next, focus on complete contracts. A first thing to note is the stability of DA wages. These wages allocate most of the surplus to the short side of the market. ${ }^{19}$ Wages in BN are slightly less extreme and much more volatile. We saw in section 4.2, however, that the number of trades in $\mathrm{BN}$ is low for complete contracts, so it is difficult to draw conclusions from these observations.

With incomplete contracts, wages are averaged across trades that workers responded to by choosing high effort and those that yielded low effort. The volatility across time and any treatment effects observed in the right panel of figure 3 may therefore be a consequence of changes in wages for given effort choice or changes in effort choices ( $c f$. section 4.4). Nevertheless, two regularities appear. First, wages are higher with excess demand than with excess supply. Second, average wages are higher in BN than in DA (as noticed in table 4). The former observation (which also holds for complete contracts) is predicted both when assuming selfish preferences and for inequity-aversion. The data show that the difference is statistically significant: the average wage in $\mathrm{BN}$ is higher with excess demand than with excess supply $(p=0.085)$ and the same holds for DA $(p=0.024){ }^{20}$ The second observation (higher wages in $\mathrm{BN})$ is predicted by $H_{2}\left(w_{B N}(I C)>w_{D A}(I C)\right.$.). The formal (Wilcoxon) test of this hypothesis is based on 11 paired observations and shows that the difference is statistically significant $(p=0.01) .{ }^{21}$ Hence, we once again reject the null based on selfish preferences in favor of the alternative hypothesis based on inequity-aversion.

\footnotetext{
${ }^{19}$ With excess demand the average wage in DA is 46.2 , implying that $87 \%$ of the surplus (30) is absorbed by the workers. With excess supply, the average DA wage of 20.8 means that only $3 \%$ if the surplus goes to the workers.

${ }^{20}$ We pool data across complete and incomplete contracts to obtain 10 excess supply observations and 11 excess demand observations.

${ }^{21}$ Testing separately for excess supply (5 paired observations) and excess demand (6 paired observations) supports this conclusion ( $p=0.075$ and $p=0.043$, respectively). To further test the wage differences between BN
} 
To summarize the results for wages: (1) market imbalance gives most of the surplus to the short side of the market; (2) complete contracts give higher wages in case of excess demand but not for excess supply; (3) wages are higher in BN than in DA.

Finally, we consider the effect of a worker's reputation on firms' bids and transaction wages in BN. Figure 4 shows these relationships.

Figure 4: Wages and Worker Reputation
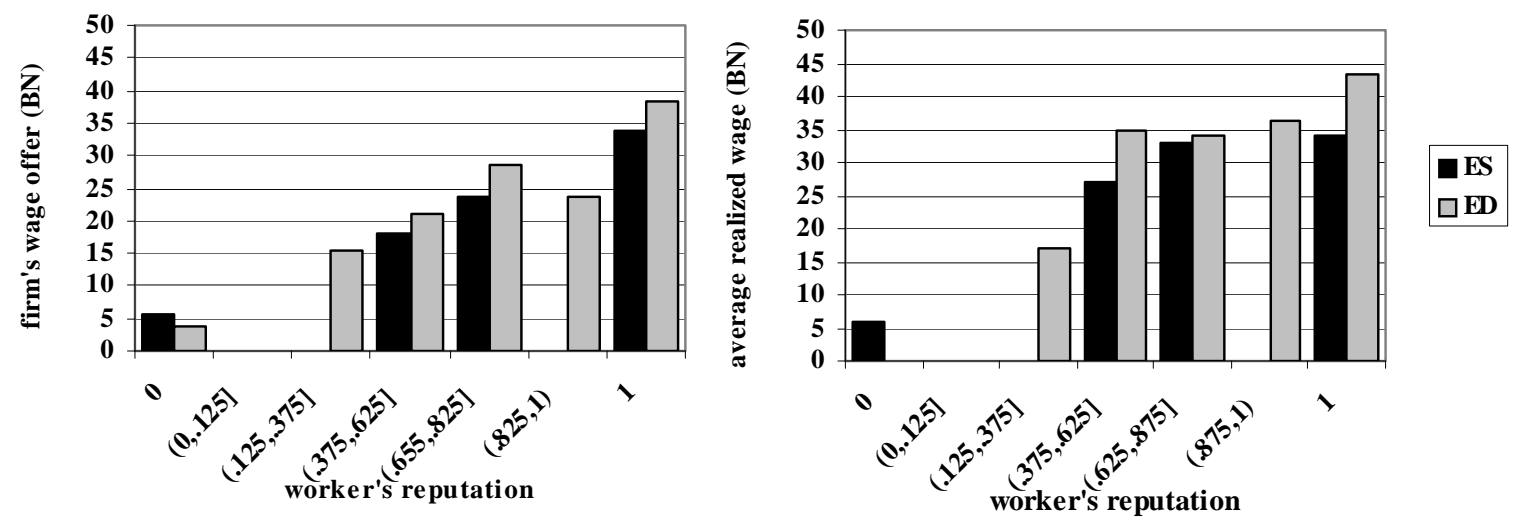

Notes. Bars give average wage offers (left panel) and average realized wages (right panel) in BN, per reputation category. The reputation is measured as the number of times the worker previously chose high effort divided by the number of previous emplyments (only for rounds 11-30). ES=excess supply; ED=excess demand.

Of course, only the treatment with incomplete information is considered, because there is no worker reputation building when contracts are complete. The worker's reputation is measured as the number of previous high effort choices, divided by the number of previous employments. This measure is at the core of our research design as it captures the information about workers, which is transmitted through the firms' information network.

The left panel of figure 4 shows that wage offers in BN strongly depend on the worker's history. With one exception, wage offers increase monotonically in the worker's reputation. ${ }^{22}$ Moreover, with excess supply workers have either a reputation of no high effort or of choosing high effort at least $37.5 \%$ of the time (there are no observations for the second and third reputation categories). Finally, if workers have a reputation larger than zero, wage offers are higher in excess demand than in excess supply.

and DA we also ran a random-effects tobit regression including dummies for BN and excess demand as well as their interaction as independent variables. The results confirm the conclusions from the non-parametric tests. The coefficient for $\mathrm{BN}$ is positive and significant at the $10 \%$-level ( $p=0.068$ ), (weakly) indicating that with excess supply, wages are higher in BN than in DA. A chi-square test on the sum of the coefficients for excess demand and the interaction term rejects the null hypothesis that this sum is equal to 0 in favor of a positive sum $(p<0.01)$. This means that with excess demand, wages are higher in BN than in DA.

${ }^{22}$ The only exception (wages offered in excess demand to workers with a reputation just below 1) can be attributed to a low number of observations (13) combined with one firm making very low offers to workers with this reputation in three different rounds (each of which was rejected). 
The right panel of the figure shows average transaction wages, i.e., it shows the subset of wage offers from the left panel that were accepted by the workers. The set of rejected offers includes relatively many low wages so that the average levels in the right panel are higher than in the left panel (for workers with a positive reputation). In particular, some firms tend to offer low wages for reputations between 0.375 and 0.825 (yielding average wages between 18.1 and 27.5). However, the workers willing to give high effort only accept the high wage offers, yielding average transaction wages between 26.9 and 35. As a consequence, the relationship between reputation and realized wages turns out to be more like a step-function than like a monotonically increasing function: it seems to matter less whether the worker chose high effort more often, as long as reputation is not too low. ${ }^{23}$

\subsection{Effort Choices}

Given that the rational high effort choice is virtually always made in the complete contracts case ( $c f$. table 4) we focus only on the incomplete contract treatments. To start, figure 5 shows the development over time of the fraction of high effort choices. Once again we present 3period moving averages to smooth out period-to-period volatility.

Figure 5: Fraction of High Effort Choices

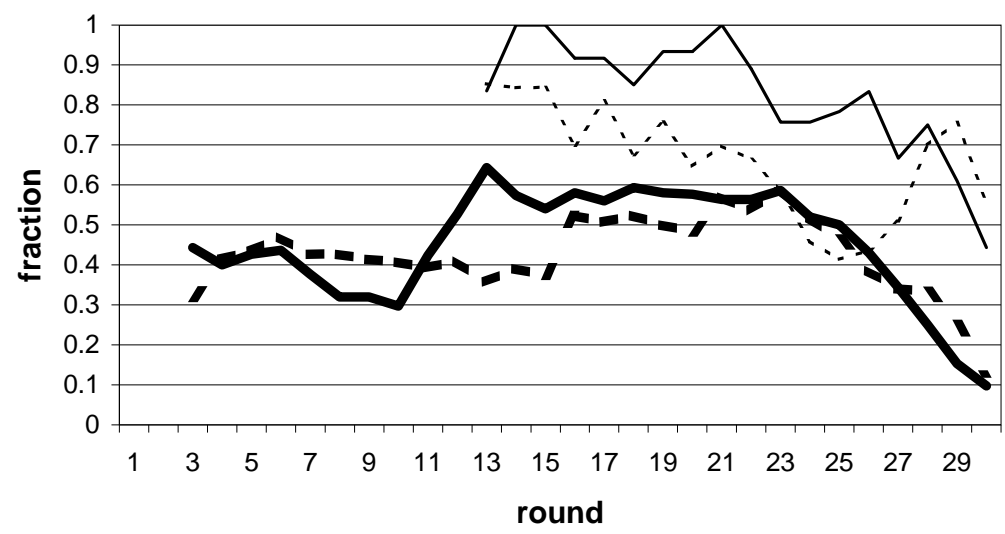

Notes. The figure shows 3-period moving averages of the fraction of high effort choices. Dashed lines show fractions for excess supply and solid line reflect excess demand. Thick lines show effort choices following trades in $\mathrm{DA}$ and thin lines for BN.

The graph shows three noticeable patterns in the dynamics. First, as we saw in table 4, when $\mathrm{BN}$ are introduced, workers are more willing to choose high effort, though this occurs more directly with excess demand than with excess supply. Second, there is a clear end effect, in

\footnotetext{
${ }^{23}$ Interestingly, theoretical models of indirect reciprocity predict precisely this kind of step-function (Nowak and Sigmund 1998; Seinen and Schram 2006).
} 
three of the treatments, with the fraction of high effort choices dropping severely in the last 5 rounds. However, note that in BN with excess supply the fraction of high effort increased substantially during rounds 25-28; this can be attributed to the substantial increase in the average wages for this case, as shown in the right panel of figure 3. Third, high effort is chosen more often after a bilateral trade than after a market trade.

Because effort choice depends on the wage received, we cannot draw conclusions about the effect of market imbalance or of the channel chosen on effort choice without correcting for the wage. For example, we know from the previous subsection that average wages are higher in $\mathrm{BN}$ than in DA. To determine whether the higher effort in $\mathrm{BN}$ is only a consequence of the higher wage or that the channel itself also affects the effort level, we ran a random effects probit model explaining (high) effort as a function of wage, market imbalance and channel, as well as interaction term between market imbalance and channel. We correct for the round of play. The results are presented in table $5 .^{24}$

Table 5: Random Effects Probit for Effort Choice

\begin{tabular}{|l|c|c|}
\hline Variable & coefficient & absolute z-value \\
\hline Constant & -6.691 & $2.33^{* *}$ \\
\hline (round-10)/10 & 0.753 & 1.16 \\
\hline (round-10) $2 / 100$ & -0.665 & $2.13^{* *}$ \\
\hline excess demand & 4.617 & 1.57 \\
\hline $\mathrm{BN}$ & -0.199 & 0.66 \\
\hline $\mathrm{BN}$ in excess demand & 0.979 & $2.38^{* *}$ \\
\hline (wage in excess demand)/10 & 0.717 & $6.55^{* * *}$ \\
\hline (wage in excess supply)/10 & 2.195 & $2.55^{* *}$ \\
\hline
\end{tabular}

Notes. The table presents the results of a random effects probit regression model where the dependent variable is a dummy indicating whether or not worker $i$ in market $j$ chose high effort in round t. Formally, it gives the estimated maximum likelihood coefficient vector $\beta$ in $\operatorname{Pr}_{t}^{i j}=\Phi\left(X_{t}^{i j \prime} \beta+\mu^{j}\right)$ where $\operatorname{Pr}_{t}^{i j}$ gives the probability that $i$ of $j$ chooses high effort in $t$. $\Phi$ denotes the cumulative normal distribution and $X$ is the vector of independent variables described in the first column of the table. $\mu^{j}$ is a (white noise) market-specific error that corrects for the dependencies across individual decision in the same market (the fraction of total variance captured in $\mu^{j}$ is captured by parameter $r h o=0.10$ ). Absolute $z$-values are in parentheses. $*=$ statistically significant at $10 \%$-level; $* *=$ statistically significant at $5 \%$-level; $* * *=$ statistically significant at $1 \%$-level.

These results show that there is no direct effect of market imbalance on effort choice after a DA trade (the coefficient for excess demand is not significant). To test whether market imbalance matters after a BN trade, we need to test whether the sum of the coefficients for 'excess demand' and 'BN in excess demand' differs from zero. A $\chi 2$ test indicates that it does

\footnotetext{
${ }^{24}$ Because the regression is only concerned with the rounds with BN, we normalize the first of these rounds to 1. To account for the end effect observed in figure 6, we include a quadratic form of the round in the regression equation (the results of which do indeed reflect this end effect). Finally, we allow the effect of wage on effort to be different for excess demand than for excess supply.
} 
$(p<0.01)$. Hence, after correcting for wages in $\mathrm{BN}$, high effort is more often chosen in excess demand than in excess supply. What appears to be happening is that workers compensate for their low number of trades in the latter case by exploiting high wage offers more often than when there are more firms than workers.

The insignificant coefficient for BN shows that with excess supply -after correcting for wages- there are no differences in effort choices between BN and DA. To investigate whether these differences exist for excess demand, we test whether the sum of the coefficients for BN and the interaction term differs from zero. Once again, a $\chi 2$ test indicates that it does $(p<0.01)$. Hence, -in support of $H_{1}\left(e_{B N}(I C)>e_{D A}(I C)\right)$ - high effort is more often chosen in excess demand after a bilaterally negotiated trade even after correcting for wage differences between BN and DA. For excess supply, the higher effort chosen in BN can be completely attributed to the (significantly) higher wages in BN than in DA, as discussed in the previous subsection.

Finally, wage does indeed strongly affect the effort chosen, in both market conditions. The effect is much larger with excess supply but statistically stronger in excess demand. This last result is a consequence of how workers respond in a situation characterized by incomplete contracts and unemployment. Most are willing to respond strongly to high wages by giving a high effort, partly because this improves their reputation for the future. However, as discussed above, some wish to compensate for a low number of contracts across rounds and exploit high wages by choosing low effort. This gives a relatively high variance and lower statistical power of the effect of wages on effort choice.

Though the coefficients in table 5 are informative about the existence of effects on effort choice, they do not reveal the magnitude of the effects. To this end, we determine the marginal effects of the most important variables. Consider first the difference in the probabilities of high effort in BN compared to DA. We calculate these separately for excess demand and excess supply and do so for the (middle) round 20. For excess demand we find that at the equitable wage of 35, the estimated probability of high effort is 20.4 percentage points higher in BN than in DA. For a more market-conforming wage of 45 , high effort is only 8.6 percentage points more likely in BN. In excess supply the effect of $\mathrm{BN}$ is negative (though insignificant, see table 6): for a wage of 35 high effort is now 4.9 percentage points less likely in BN than in DA and for a wage of 25 the probability of high effort is 3.8 percentage points lower in BN. Hence, ceteris paribus, the effects on effort choice of negotiating bilaterally are larger in excess demand than in excess supply. 
We have observed above, however, that there are generally wage differences between BN and DA. We therefore calculate the marginal effects of changing the wage from one that conforms to the market imbalance (45 and 25, for excess demand and excess supply, respectively) to an equitable one of 35 . Under excess demand a wage of 35 yields in the DA a 19.3 percentage points lower frequency of high effort than a wage of 45 . In the $\mathrm{BN}$ the reduction in the frequency of high effort is 7.5 percentage points. Under excess supply a wage of 35 yields in the DA a 72.7 percentage points higher frequency of high effort than a wage of 45. In the BN the increase in the frequency of high effort is of 71.6 percentage points. This confirms our conclusion that in excess supply wage differences are the driving force in the effort differences between DA and BN.

\subsection{Realized Surplus}

Figure 6 shows the average realized surplus across treatments. Recall that in any treatment, this is maximized when high effort is chosen. Consequently, the development of surplus over

Figure 6: Average Realized Surplus

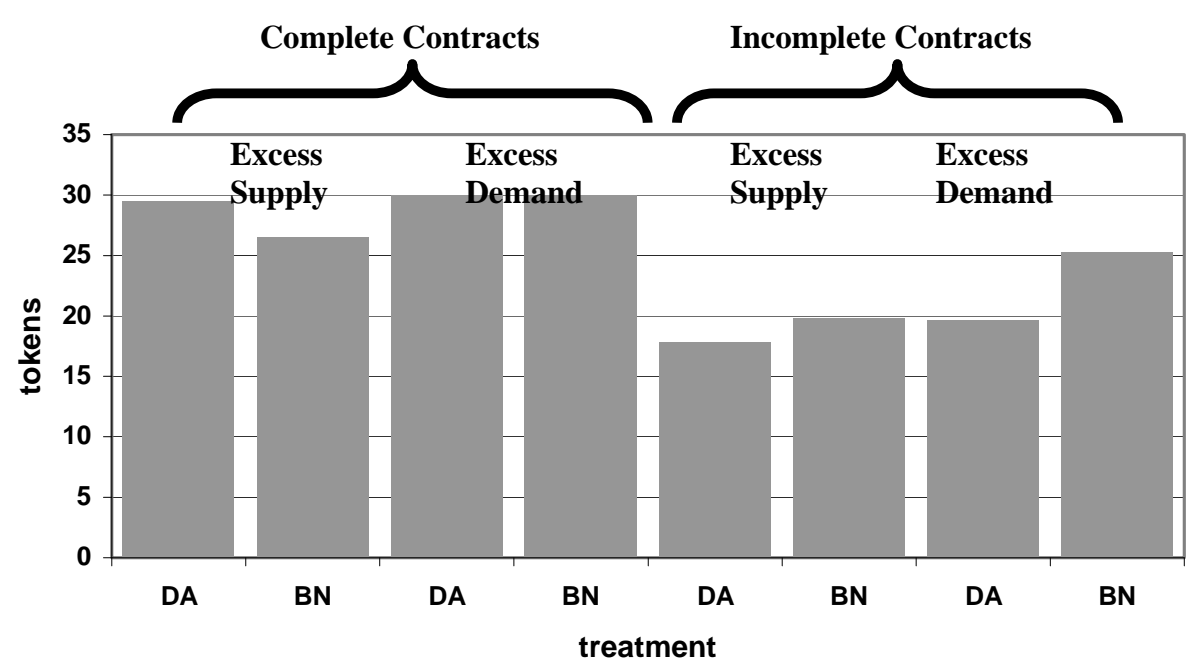

Notes. Bars represent average realized surplus in a treatment. DA=double auction; $\mathrm{BN}=$ bilateral negotiations.

time with incomplete contracts is fully determined by the development of high effort choices shown in figure 5. The comparative statics observed for effort choice therefore carry over to surplus as well (e.g., trading bilaterally realizes higher surplus than trading on the market when contracts are incomplete).

A first thing to note from the figure is that surplus is close to its maximum (30) when contracts are complete. In these cases the larger part of this surplus is allocated to the short side of the market. It turns out that the division between firms and workers is more equitable 
in $\mathrm{BN}$ than in DA. ${ }^{25}$ This latter result supports the assumption made in section 3 that equity concerns are more important in BN than in DA.

For incomplete contracts, we know from the analysis in preceding sections that compared to DA, in BN (i) wages are significantly higher; (ii) these higher wages yield significantly higher effort choices; and (iii) even for equal wages, high effort is significantly more likely to be chosen in BN (when there is excess demand). ${ }^{26}$ Hence, surplus is significantly higher in $\mathrm{BN}$ than in $\mathrm{DA}$, which supports hypothesis $\mathrm{H}_{4}: \pi_{f}(B N, I C)+\pi_{l}(B N, I C)>\pi_{f}(D A, I C)+$ $\pi_{l}(D A, I C)$. This support is also found in a direct test comparing realized surplus (the average across all decisions per market) in BN and DA for the incomplete contracts case, though the difference is only statistically significant for the five observations with excess demand $(\mathrm{p}=0.075)$.

\subsection{Bilateral Negotiations without Information}

There are two differences between trading in BN and in DA under incomplete contracts. First, the difference we have been stressing is that in BN firms receive information about workers' past choices. Second, trades in BN are truly bilateral whereas the DA environment involves multiple traders. It is conceivable that either or both of these lead to the observed differences, since bilateral trading per se may trigger reciprocal behavior. To investigate this, we collected data from 6 additional markets with no information in $\mathrm{BN}$ - an additional 42 participants to the 147 of the four treatments discussed above. In these markets the only difference between the two channels is the bilateral nature of BN. In all other respects these sessions were identical to the previous ones. We focused on the treatment most commonly investigated in the literature on gift exchange (which is also our treatment where the differences between BN and DA were large), to wit, excess supply with moral hazard.

Table 6 shows the key statistics (and reproduces the corresponding results from table 4 for the case with information) for rounds 11-30, in which trading in BN is possible. Most notable is that far fewer trades are bilateral when there is no information about worker reputation. The proportion of bilateral trades is in fact quite similar to that under complete contract, when information about workers' performance is of little use. Moreover, virtually all of the BN trades observed are in the first half of these rounds. In the last 10 rounds only 1 of the 120 trades was bilateral. The reason is simply that the relatively high wages in $\mathrm{BN}$ are

\footnotetext{
${ }^{25}$ When scarce, firms get $88 \%$ of the surplus in DA versus $67 \%$ in BN; when redundant, they acquire $5 \%$ in DA and $26 \%$ in $\mathrm{BN}$.

${ }^{26}$ For incomplete contracts, we cannot directly compare the differences between DA and BN with respect to inequity concerns because of the confounding differences in realized surplus.
} 
Table 6: Key Statistics

\begin{tabular}{|l|c|c|c|c|c|c|c|}
\hline & $\begin{array}{c}\text { \% of } \\
\text { possible } \\
\text { trades }\end{array}$ & $\begin{array}{c}\text { \% } \\
\text { trades } \\
\text { in BN }\end{array}$ & $\begin{array}{c}\text { Average } \\
\text { DA } \\
\text { wage }\end{array}$ & $\begin{array}{c}\text { Average } \\
\text { BN } \\
\text { wage }\end{array}$ & $\begin{array}{c}\text { \% high } \\
\text { effort DA }\end{array}$ & $\begin{array}{c}\text { \% high } \\
\text { effort BN }\end{array}$ \\
\hline \multirow{2}{*}{$\begin{array}{l}\text { Excess sup- } \\
\text { ply \& IC }\end{array}$} & no-info & 96.7 & 10.3 & 16.0 & 27.2 & 31.0 & 14.2 \\
\cline { 2 - 8 } & info & 96.5 & 28.5 & 18.3 & 25.9 & 39.1 & 49.1 \\
\hline
\end{tabular}

Notes. All data refer to rounds 11-30. IC= incomplete contracts; no-info= no information about worker reputation is provided in $\mathrm{BN}$; info= information about worker reputation is provided in $\mathrm{BN}$; \% of possible trades is number of realized trades as percentage of possible trades. $\%$ of trades in $B N$ is number of bilateral deals as percentage of realized trades. Average $D A$ wage= average wage realized in the double auction; Average $B N$ wage= average wage in bilateral deals. \% high effort $D A=$ number of high effort choices after double action trade as percentage of trades in double auction; \% high effort $B N=$ number of high effort choices after bilateral deal as percentage of bilateral deals.

exploited very frequently when there are no consequences for the worker's reputation. Note that the DA trades and decisions are quite comparable with and without information, though the slightly lower frequency of high effort choice (31.0\% vs. 39.1\%) when there are no reputational repercussions is noteworthy. The data shown in the table make it clear that the presence of information is crucial for high surplus, since without information high effort in $\mathrm{BN}$ is only $14.2 \%$ - not higher than in the DA (in fact, lower, but based on far fewer observations).

\subsection{Summary of the Results}

We summarize our results by comparing behavior in BN and DA for the four treatment cells of the initial design and the treatment without information that we have just presented in section 4.6.

(1) When contracts are complete and there is excess supply, firms face a relatively easy situation. They know that they can create high surplus by choosing high effort (which virtually all of them do) and they have the advantage of being on the short side of the market. We observe that they are hesitant to enter BN. If they do, they offer relatively low wages (at which they would keep most of the high surplus). Because less than 50\% of these offers are accepted, in the end roughly only one-tenth of all trades are bilaterally negotiated. Wages in DA allocate almost the complete high surplus to the firm, whereas the few BN trades that take place share approximately $25 \%$ of this surplus with the worker.

(2) With complete contracts and excess demand firms know they will choose high effort (which they do) but they also have to compete with other firms for the scarce workers. Therefore, almost all firms propose negotiations, but 50\% of the workers decline the opportunity offered. The workers that do decide to negotiate are offered wages that give 
them a larger cut of the pie than the firm, but the average offer is relatively low compared to wages on the market. Only $25 \%$ of these offers are accepted, resulting in approximately one-tenth of the trades being bilateral. In these bilateral trades, workers receive roughly two-thirds of the surplus whereas they end up with almost $90 \%$ of the surplus when they trade on the double auction market.

(3) The case with incomplete contracts and excess supply is the situation most studied in the literature on gift exchange in the labor market (though these previous studies only had the possibility of trading in a DA). This is an interesting scenario because the firms have the advantage of being on the short side of the market but the disadvantage of facing the moral hazard of the worker's effort choice. When offered the possibility, firms are hesitant to enter $\mathrm{BN}$. If they do enter, they offer low wages compared to the other treatments but these offers meet with the highest acceptance rate of all treatments. This leads to roughly $30 \%$ of all trades bypassing the market. Though wages are relatively low in $\mathrm{BN}$, they are even lower in DA. While the average worker does respond to a higher wage with higher effort, workers do regularly exploit high offers by choosing low effort. Note that due to excess supply any particular worker is, on average, only involved in a trade once every 2.5 rounds. Apparently, some workers take the opportunity to make a high profit when they have a chance to do so. Because of being exploited in some rounds, firms earn on average less in BN than in DA, though a higher average surplus is observed in $\mathrm{BN}$. The results from our additional treatment shows that the high $\mathrm{BN}$ trading and surplus can be attributed to the presence of information in the bilateral negotiations; without information we find that the fraction of trades through the $\mathrm{BN}$ and the fraction of high effort choices in the BN are substantially lower than with information.

(4) Finally, when contracts are incomplete and there is excess demand firms are at a disadvantage on two dimensions. They generally offer to trade bilaterally, but only 50\% of the workers accept this opportunity. When they do, they typically get a relatively high offer and roughly half of the workers accept the wage, resulting in approximately $30 \%$ of all trades being negotiated bilaterally. Wages in DA are lower than in BN because BN offers can be conditioned on the worker's history of effort choices. This indeed yields regular high effort choices, with their likelihood being higher, the higher the wage (and higher in BN even after correcting for wage differences). As a consequence, both firms and workers earn on average more after a bilateral trade than after a trade on the market. 
With respect to the formal hypotheses derived in section 3, we rejected the null hypotheses based on selfish preferences in favor of the following alternatives: $H_{3}$ (more bilateral trades for incomplete contracts); $H_{2}$ (higher wages in $\mathrm{BN}$ ); and $H_{1}$ (more high effort in $\mathrm{BN}$ ); $H_{4}$ (higher surplus in BN).

\section{Conclusions}

An important tradeoff that firms face when recruiting new personnel is between the multiple contacts and wage transparency of the market on the one side and the limited contacts but better information transmitted through social networks on the other. Field studies have shown that firms regularly bypass the market and choose to recruit through their social networks. Our study replicates this observation in a controlled laboratory environment and provides a rationale for it. We show that it is the interaction between social preferences, the incompleteness of contracts and the existence of information about a worker's past performance that provides a reason for firms to forgo market opportunities and bilaterally negotiate with a worker. Given that the information transmitted through a firm's network concerns the worker's trustworthiness in jobs with moral hazard, bilateral negotiations supported by information generated in the network provide an alternative for market trading. We observed that approximately $30 \%$ of all job contracts were bilaterally negotiated in this case as opposed to only $10 \%$ when contracts were complete.

Our results show that -contrary to what simple economic intuition might suggest- surplus is higher when trades are bilateral. Of course, this does not imply that a situation with only bilateral trading would maximize surplus. The choice of channels is endogenous in our experiment and this yields an increase in surplus compared to only market trading. How an exogenously imposed limit on market trading would affect welfare is an open question that could be studied in future research. Intuitively, we doubt that such restrictions would have a positive effect on welfare. In our experiments and in the world outside of the laboratory, it is important that bilateral negotiators have the market as an outside option.

Together with the results presented by Brown et al. (2004) an interesting picture arises from our results. Whereas we show that information about a worker's past performance, as disclosed in information networks increases the surplus from first time wage contracts, they show that -once a good first match has been found- bilateral trading on extended contracts increases surplus even further. Hence, firms first call upon their networks to help find a trustworthy employee and offer such an employee a wage based on indirect reciprocation of this worker's past performance in other jobs. Once they have found a worker, they base their 
continuing relationship on mutual direct reciprocation where workers respond to high wages with high effort (as we also observe in the one round interaction we study) and vice versa.

In our model, the source of reciprocation is the inequity-aversion of workers. If enough workers dislike exploiting high wage offers firms may be willing to take the risk of offering one. Networks are a source of information for firms about the likelihood that a particular worker will exploit a high wage. Because of anonymity this information is not disseminated through a centralized market. This is why centralized market institutions may be imperfect, allowing alternative institutions (i.c., information networks) to increase surplus. 


\section{References:}

Alós-Ferrer, C. and G. Kirchsteiger (2003), "Does Learning Lead to Coordination on Market Clearing Institutions?,” Working Paper No. 0319, Department of Economics, University of Vienna.

Albrecht, JW and B. Axell (1984), “An Equilibrium Model of Search Unemployment,” The Journal of Political Economy 92-5, pp. 824-840.

Baker, G.P. (1992), "Incentive Contracts and Performance Measurement," The Journal of Political Economy 100-3, pp. 598-614

Barron, J. and J. Bishop (1985), “Extensive Search, Intensive Search, and Hiring Costs: New Evidence on Firm Hiring Activity,” Economic Inquiry, 23, 363-382.

Behrenz, L. (2001), "Who Gets The Job And Why? An Explorative Study Of Employers ' Recruitment Behaviour,” Journal of Applied Economics IV-2, pp. 255-278.

Bentolila, S., C. Michelacci and J. Suárez (2004), “Social Contacts and Occupational Choice,” CEPR Discussion Paper No. 4308.

Bolton, G., and Ockenfels, A. (2000), 'ERC: A Theory of Equity, Reciprocity and Competition.' American Economic Review, vol. 90, pp. 166-193.

Bolton, G., E. Katok and A. Ockenfels (2004), "How Effective are Electronic Reputation Mechanisms? An Experimental Investigation, Management Science 50, 1587-1602.

Bontemps, C. J-M. Robin and G.J. van den Berg (2000), "Equilibrium Search with Continuous Productivity Dispersion: Theory and Nonparametric Estimation,” International Economic Review 41-2, pp. 305-358.

Boorman, S.A. (1975), “A Combinatorial Optimization Model for Transmission of Job Information Through Contact Networks, “ Bell Journal of Economics 6, 216-249.

Boxman, E.A.W. and H.D. Flap (1991), “Informele contacten en Beroepspositie van Managers”, Tijdschrift voor Arbeidsvraagstukken 7-1, pp. 51-60.

Brandts, J. and G. Charness (2004), "Do Labour Market Conditions Affect Gift Exchange? Some Experimental Evidence,” Economic Journal, 114, 684-708.

Brown, M., Falk, A. and Fehr, E. (2004), "Relational Contracts and the Nature of Market Interactions," Econometrica, 72, 3, 747-780.

Brown, M., Falk, A. and Fehr, E. (2008), “Competition and Relational Contracts: The Role of Unemployment as a Disciplinary Device,” IZA Discussion Paper 3345, February 2008.

Brown, M. and C. Zehnder (2005), “Credit Registries, Relationship Banking and Loan Repayment,” IEW Working Paper 240, May 2005.

Burdett K. and D.T. Mortensen (1980), "Search, Layoffs, and Labor Market Equilibrium," The Journal of Political Economy 88-41, pp. 652-672.

Calvó-Armengol, A. (2004), “Job Contact Networks,” Journal of Economic Theory, 115, 191-206.

Camerer, C. (2003), “Behavioral Game Theory”, Russel Sage Foundation, New York.

Chan, W. (1996), “External Recruitment versus Internal Promotion,” Journal of Labor Economics 14-4, pp. 555570.

Charness, G. (2004), “Attribution and Reciprocity in an Experimental Labor Market,” Journal of Labor Economics 
Charness, G. and M. Rabin (2002), “Understanding Social Preferences with Simple Tests,” The Quarterly Journal of Economics 117 (3), 817-869,

Coleman, J.S. (1988), “Social Capital in the Creation of Human Capital,” American Journal of Sociology 94, pp. s95-s120.

Corcoran, M., L. Datcher and G.J. Duncan (1980), “Most workers find jobs through word of mouth”, Monthly Labour Review, August, pp. 33-35.

Cox, J., D. Friedman, and S. Gjerstad (2007), “A Tractable Model of Reciprocity and Fairness”; Games and Economic Behavior 59, 17-45.

Davis, D., G.W. Harrison and A.W. Williams (1993), "Convergence to Nonstationary Competitive Equilibria: An Experimental Analysis”, Journal of Economic Behavior and Organization 22, 305-326.

Davis, D. and C. Holt (1993), “Experimental Economics”, Princeton University Press.

Eguchi, K. (2005), “Job Transfer and Influence Activities,” Journal of Economic Behavior and Organization 562, pp. 187-197

Engelmann, D. and U. Fischbacher (2004), "Indirect Reciprocity and Strategic Reputation Building in an Experimental Helping Game”, mimeo, University of Zürich.

Falk, A. and E. Fehr (2003), “Why Labour Market Experiments?,” Labour Economics, 10, 399-406.

Falk, A. and M. Kosfeld (2004), "The Hidden Costs of Control," American Economic Review 96, 2006, 16111630.

Fehr, E. and A. Falk (1999), "Wage Rigidities in a Competitive Incomplete Contract Market”, Journal of Political Economy 107, 106-134.

Fehr, E., Gächter, S., and Kirchsteiger, G. (1997), “Reciprocity as a Contract Enforcement Device: Experimental Evidence," Econometrica, 65, 833-860.

Fehr, E., Kirchsteiger, G. and Riedl, A. (1993). 'Does Fairness Prevent Market Clearing? An Experimental Investigation.’ Quarterly Journal of Economics, vol. 108, 2, pp. 437-460.

Fehr, E., Kirchsteiger, G. and Riedl, A. (1998). 'Gift Exchange and Reciprocity in Competitive Experimental Markets.’ European Economic Review, vol. 42, pp. 1-34.

Fehr, E., and K.M. Schmidt (1999): “Fairness, Competition, and Inequality”, Quarterly Journal of Economics 114 (3): 817-868.

Flap, H. and B. Volker (eds.) (2004), Creation and returns of social capital. A new research program. Routledge. Taylor \& Francis Group: London \& New York.

Granovetter, M.S. (1974), Getting a Job: A Study of Contacts and Careers. Basic Books; Cambridge, MA.

Granovetter, M.S. (1995), Getting a Job: A Study of Contacts and Careers, 2nd edition. University of Chicago Press, Chicago.

Goldthorpe, J.H. (2000), On Sociology: Numbers, Narratives, and the Integration of Research and Theory, Oxford University Press.

Gorter, C., P. Nijkamp, and P. Rietveld (1993), “'The Impact of Employers’ Recruitment Behaviour on the Allocation of Vacant Jobs to Unemployed Job Seekers," Empirical Economics 18, pp. 251-269.

Gorter, C. and J. van Ommeren (1999), “Sequencing, Timing and Filling Rates of Recruitment Channels,” Applied Economics 31, pp. 1149-1160. 
Hannan, L., Kagel, J. and Moser, D. (2002). 'Partial Gift Exchange in Experimental Labor Markets: Impact of Subject Population Differences, Productivity Differences and Effort Request on Behavior.' Journal of Labor Economics, vol. 20, pp. 923-951.

Hicks, J. R. (1932), The Theory of Wages, reprinted in The Theory of Wages, 2nd edn, London, Macmillan, 1963.

Holt, C. H., L. Langan and A. Villamil (1986): "Market Power in Oral Double Auctions," (with L. Langan and A. Villamil), Economic Inquiry, 24, January 1986,107-123.

Holzer, H. (1987), “Search Method Use by Unemployed Youth,” Journal of Labor Economics, 6, 1-20.

Kirchsteiger, G., M. Niederle and J. Potters (2005), "Endogenizing Market Institutions. An Experimental Approach,” European Economic Review 49, 1827-1853.

Kugler, A. (2003), “Worker referrals and efficiency wages,” Labour Economics, 10, 531-556.

Kugler, T., Z. Neeman and N. Vulkan (2004), "Market versus Negotiations: An Experimental Investigation,” mimeo, University of Arizona.

Kreps, D.M. and R. Wilson (1982), “Reputation and Imperfect Information,” Journal of Economic Theory 27, pp. 253-279.

Lin, N., W.M. Ensel and J.C. Vaughn (1981), "Social Resources and Strength of Ties: Structural Factors in Occupational Status Attainment,” American Sociological Review 46, pp. 393-405.

Lin, N., K. Cook and R.S. Burt (eds.) (2001), Social Capital. Theory and Research. Aldine de Gruyter, New York.

Lindeboom, M., J. van Ours and G. Renes (1994), "Matching Employers and Workers: An Empirical Analysis on the Effectiveness of Search,” Oxford Economic Papers 46, pp. 45-67.

Marsden, P. (2001), “Interpersonal Ties, Social Capital and Employer Staffing Practices,” In Lin et al. (eds.) Social capital. Theory and research. pp. 105 - 127. New York, Aldine de Gruyter.

McCall, J.J. (1970), “Economics of Information and Job Search,” The Quarterly Journal of Economics 84-1, pp. 113-126.

Milgrom, P.R. (1988), “Employment Contracts, Influence Activities, and Efficient Organization Design,” The Journal of Political Economy 96-1, pp. 42-60.

Montgomery, J. (1991), "Social Networks and Labor-Market Outcomes: Toward an Economic Analysis," American Economic Review, 81, 5, 1408-1418.

Mortensen, D.T. (1970), Job Search, the Duration of Unemployment, and the Phillips Curve,” The American Economic Review 60-5, pp. 847-862.

Mortensen, D. and C. Pissarides (1999), “New Developments in Models of Search in the Labour Market,”In (O. Ashenfelter and D. Card, eds.) Handbook of Labour Economics, vol. 3B, Amsterdam: Elsevier Science, NorthHolland.

Neeman, Z., and N. Vulkan (2002),“Markets versus Negotiations: the Predominance of Centralized Markets,” mimeo, Boston University.

Neugebauer, T., A. Paulsen and A.J.H.C. Schram (2008), “Fairness and Reciprocity in the Hawk-Dove game”, Journal of Economic Behavior and Organization 66, 243-250.

Nowak, M.A. and K. Sigmund (1998): "Evolution of indirect reciprocity by image scoring," Nature, 393, 573-577. 
Phelps, E.S. (1968), “Money-Wage Dynamics and Labor-Market Equilibrum,” The Journal of Political Economy 76-4, pp. 678-711.

Phelps, E.S. (1970), Microeconomic Foundations of Employment and Inflation Theory, Norton, New York.

Pissarides, C.A. (1990), Equilibrium Unemployment Theory, Blackwell, Oxford.

Rees, A. (1966), “Information Networks in Labor Markets,” American Economic Review, 56, 1-2, 559-566.

Rogerson R., R. Shimer and R. Wright (2005), "Search-Theoretic Models of the Labor Market: A Survey,” Journal of Economic Literature 43-4, pp._959-988

Roth, A.E., Prasnikar, V., Okuno-Fujiwara, M., and Zamir, S. (1991), "Bargaining and Market Behavior in Jerusalem, Ljubljana, Pittsburgh, and Tokyo: An Experimental Study," American Economic Review, vol. 81, December 1991, 1068-1095.

Russo G., P. Rietveld, P. Nijkamp and C. Gorter (2000), "Recruitment Channel Use and Applicant Arrival: An Empirical Analysis,” Empirical Economics 25-4, pp. 673-697.

Russo, G., C. Gorter and R. Schettkat (2001), “Searching, Hiring and Labor Market Conditions,” Labor Economics 8, pp. 553-71.

Rust, J., G. Hall (2003), “Middlemen versus Market Makers: A Theory of Competitive Advantage,” Journal of Political Economy 111, 353-403.

Schram, A.. J. Brandts, J. and K. Gërxhani (2007), “Inequity Aversion in a Gift-Exchange Experiment”, mimeo, University of Amsterdam.

Seinen, I and Schram, A. (2006), "Social Status and Group Norms: Indirect Reciprocity in a Helping Experiment, “ European Economic Review 50, 581-602.

Stigler, G.J. (1961), “The Economics of Information,” The Journal of Political Economy 69-3, pp. $213-225$.

Stigler, G.J. (1962), “Information in the Labor Market,” The Journal of Political Economy 70-5. Part 2: Investment in Human Beings, pp. 94-105

Tallroth, E. (2003), “Endogenous Market Structures in the Laboratory: Evidence,” mimeo, George Mason University.

Van Ours, J. C. and G. Ridder (1991), “Cyclical Variation in Vacancy Durations and Vacancy Flows: An Empirical Analysis,” European Economic Review 35-5, pp. 1143-1155.

Van Ours, J. C. and G. Ridder (1992), "Vacancies and the Recruitment of New Employees,” Journal of Labor Economics 10-2, pp. 138-155.

Williamson, O.E. (1981), “The economics of organization: The Transaction Cost Approach,” American Journal of Sociology 87-3, pp. 548-577. 


\section{Appendix A}

This appendix gives the English translation of the original Dutch instructions for the sessions with incomplete contracts and excess supply of labor. (Italics indicate places where alternative texts were used for other treatments). The instructions were programmed as html pages. Horizontal lines indicate page separations.

\section{At the start of the experiment:}

\section{Welcome}

You are about to participate in a decision-making experiment. The instructions are simple. If you follow them carefully, you may earn a substantial amount of money. Your earnings will be paid to you in euros at the end of the experiment. This will be done privately, one participant at a time.

The monetary unit in the experiment is 'experimental francs'. At the end of the experiment francs will be converted to euros at a rate of $\mathbf{1}$ euro for $\mathbf{1 5}$ francs.

These instructions consist of 8 pages like this one. During the instructions you can page forward or backward by clicking with your mouse on 'previous page' or 'next page'. Sometimes a page will not fit on your screen. In that case you can use the scroll bar to view the whole page.

\section{Next page}

\section{Rounds and Groups}

The experiment consists of 30 rounds, preceded by 3 practice rounds. After round 10 additional instructions will be given before we proceed.

In every round you will participate in a market where hypothetical goods are traded. Buyers can buy at most one good and sellers can sell at most one good. How you can make money by trading will be explained below.

In total 7 people participate in the market. There are 2 buyers and 5 sellers. (There are 5 buyers and 2 sellers). You will have the same role in every round: either buyer or seller. That will be determined before the first practice round. The other buyers and sellers in your market will be the same other participants in every round. You do not know who they are, however. Because there are more sellers than buyers (more buyers than sellers) in each round at least three sellers (buyers) will not be able to sell (buy) the good.

The composition of markets is anonymous. You do not know with whom you are in the market. Others do not know whether they are with you.

\section{$\underline{\text { Previous page Next page }}$}

\section{Buying and Selling the Good}

If the buyer buys from a seller s/he pays an agreed upon price. How the price is determined will be explained below. 
To deliver the good, the seller may endure costs. There are two possibilities. If the seller delivers a low quality good, there are no costs. If the seller delivers a high quality good the costs are $\mathbf{2 0}$ francs.

If a buyer gets the good s/he receives a revenue in francs. If the buyer buys a low quality good this revenue is $\mathbf{1 0}$ francs. For a high quality good the revenue for the buyer is $\mathbf{5 0}$ francs.

This allows you to calculate earnings in a round, dependent on the quality.

1. The good has low quality:

Earnings for the seller $=$ agreed upon price

Earnings for the buyer $=10-$ agreed upon price

2. The good has high quality:

Earnings for the seller $=$ agreed upon price -20

Earnings for the buyer $=50$ - agreed upon price

If you do not buy or sell anything your earnings are 0 .

Previous page Next page

Phases

Each round consists of two phases.

In the first phase of a round buyers and sellers participate in a public market where each buyer can respond to an offer by any seller and vice versa.

In the second phase it is determined whether the good has low or high quality. This is determined by the seller (buyer).

Previous page Next page

\section{Phase 1}

Participation in the public market proceeds as follows. Buyers may post an offer for the good and this offer holds for every seller in the market. Sellers may post an ask price and this holds for every buyer.

On the lower half of your screen you wil see two rows of boxes. In the top row there is a box for each buyer. In the lower row there is a box for each seller.

You will recognize your own box by its yellow color.

BEWARE: buyers and sellers are randomly reallocated to boxes in every round. Therefore, you cannot keep track across rounds of what specific other participants are doing.

Previous page Next page

\section{Phase 1}

If a buyer or seller places an offer on the public market, this appears in her or his box. 
If you are a seller you will see a button 'accept' next to each buyer's box. By clicking this you indicate that you will sell the good to that buyer at that price. You can only click the button if the buyer concerned is still active on the market. If the buyer has already bought from another seller you can no longer click 'accept'. You can still see at what price that buyer bought the good (and you will see the same price in the box of one of the sellers).

If you enter an ask price lower than the highest bid by any buyer, you will automatically sell the good at the price offered by that buyer.

If you are a buyer you will see a button 'accept' next to each seller's box. By clicking this you indicate that you will buy the good from that seller at that price. You can only click the button if the seller concerned is still active on the market. If the seller has already sold to another buyer you can no longer click the button. Again, you will still see the price.

If you enter a bid higher than the lowest ask price by any seller, you will automatically buy the good at the price asked by that seller.

You may change your bid or ask as often as you like. It does hold that a buyer may only increase the own bid. A seller may only decrease the own ask.

The public market will remain open for 90 seconds. You will see the time count down on your screen. Whoever has not bought or sold when the market closes does not buy or sell the good in that round. When no more sales are possible (2 goods have been sold) the clock automatically jumps down to 5 seconds.

Previous page Next page

\section{Phase 2}

In phase 2 the seller (buyer) determines the quality of the good. S/he does this by clicking either 'high' or 'low' and confirming the choice.

As mentioned before: if the quality is low, the revenue for the buyer is 10 and the costs for the seller are 0 . If the quality is high, the revenue for the buyer is 50 and the costs for the seller are 20 .

When everyone has finished, the next round starts.

Previous page Next page

End

This brings you to the end of these instructions. When everyone is ready we will start the first of three practice rounds. These will not affect your earnings. At the start of the practice rounds we will distribute a summary of the most important parts of these instructions.

When the first practice round starts you will see at the top of your screen whether you are a buyer or seller.

If you have finished these instructions, please indicate this by clicking the button 'ready' (at the bottom of this screen). Then please wait quietly until everyone is ready. That may take a little while, so we ask for your patience.

Previous page Back to first page 


\section{Before Round 11:}

An Additional Phase

We add a third phase to each of the 20 rounds that will follow.

Therefore, from now on each round will consist of three phases. We will first give a brief overview and then provide more details about each phase.

In the first phase each buyer can propose to one seller to negotiate a price for the good separately from the other participants. The seller will be given an opportunity to indicate whether or not s/he is willing to negotiate bilaterally. The seller may also decide in phase 1 not to negotiate bilaterally with any buyer (but to only participate in the public market, instead).

In the second phase of a round buyers and sellers negotiate about a price for the good. If a buyer and seller have agreed to participate in bilateral negotiations, they negotiate privately. Any participant not involved in bilateral negotiations participates in a public market like the one in rounds 1-10. Thus, the market is opened at the same time as the private negotiations take place. Those negotiating bilaterally will see what is happening on the public market but cannot participate in it. If the negotiations do not lead to an agreement the buyer and seller concerned can switch and participate in the public market.

No one participating in the public market can observe anything that is occurring in any private negotiations.

In the third phase the quality of the good (low or high) is again determined by the seller (buyer).

\section{Next page}

\section{Phase 1}

In phase 1 buyers first indicate whether they want to immediately proceed to the public market or first want to privately negotiate with a seller. This is done using the buttons 'market' and 'negotiate'.

By clicking on 'market' the buyer indicates not wanting any private negotiations.

By clicking on 'negotiate' the buyer indicates a wish to negotiate bilaterally with a seller. Because there are more sellers than buyers (more buyers than sellers), not every seller will be invited to negotiate (it may occur that not every seller who wants to negotiate will be able to do so). A random lottery will be used to determine which seller (buyer) will be linked to a buyer (seller).

BEWARE: in every round the sellers are randomly allocated to buyers who wish to negotiate. A buyer can therefore not know whether or not s/he has previously negotiated with a seller and a seller cannot know whether s/he has previously negotiated with a buyer.

Previous page Next page 


\section{Phase 1}

If a seller is offered private negotiations with a buyer s/he must indicate whether or not s/he is willing to participate in them. This is done by clicking 'yes' or 'no' and confirming the decision.

If a buyer and seller thus agree to negotiate bilaterally the buyer is given information about the seller before the negotiations start. [This sentence was dropped in the no info sessions]

This information is the number of times that the seller chose (was confronted with) low quality and the number of times that the seller chose (was confronted with) high quality in previous rounds. [This sentence was dropped in the no info sessions]

BEWARE: the count of the numbers of low and high quality starts now. No information will be given about choices in rounds that have at this point been finished. [This sentence was dropped in the no info sessions]

Previous page Next page

\section{Phase 2}

In phase 2 buyers and sellers negotiate the price of the good.

In the market, things proceed precisely as in the first 10 rounds. The only difference is that sometimes not everyone is participating. Recall that those involved in private negotiations are not participating in the market. For these buyers and sellers you will see empty boxes in the market.

Here we explain what happens when buyers and sellers negotiate bilaterally. During these negotiations they can continuously see at the bottom of their screen what is happening in the public market.

The negotiations proceed as follows. After the buyer has seen the sellers choices (experiences) in previous rounds the buyer places a bid for the good. [In the no info sessions, this sentence read: First, the buyer places a bid for the good. ] This number is entered in the location provided after which the button 'confirm' must be clicked.

Next, the seller must indicate whether or not s/he accepts the bid. This is done by clicking 'yes' or 'no' and confirming.

If the seller accepts the bid, the buyer and seller must wait until all participants are ready before proceding to phase 3 . Participants in the market only notice this by the fact that the corresponding boxes are never activated. Therefore, no one in the market knows the results of private negotiations.

If the seller does not accept the bid, then the buyer and seller can both participate in the public market, if it has not been closed yet. On your screen you will directly enter the market.

Previous page Next page

\section{Phase 3}

In phase 3 the seller (buyer) determines the quality of the good. S/he does this, just like in the first 10 rounds, by clicking 'high' or 'low' and confirming. 
It still holds that a low quality means that the revenue for the buyer is 10 and the costs for the seller are 0 . A high quality means a buyer revenue of 50 and seller costs of 20

When everyone has finised, the next round starts.

Previous page Next page

\section{End}

This brings you to the end of these instructions. When everyone is ready we will proceed with round 11 of the experiment. We point out once more that we will start counting sellers' quality choices (experiences) now. [This sentence was dropped in the no info sessions] This information will be made known to buyers if they bilaterally negotiate with the seller concerned. [This sentence was dropped in the no info sessions]

First, we will distribute a summary of the most important parts of these instructions.

If you have finished these instructions, please indicate this by clicking the button 'ready' (at the bottom of this screen). Then please wait quietly until everyone is ready. That may take a little while, so we ask for your patience.

Previous page Back to first page 


\section{Appendix B: Derivation of the Hypotheses}

In a companion paper (Schram et al. 2007; henceforth SBG) we provide a theoretical analysis for a general case. In this appendix, we derive hypotheses for the specific parameters of our experiment.

\section{B1. Inequity-neutral Preferences}

To start, note that the theoretical predictions for the one-shot case are straightforward if we assume that it is common knowledge that all participants are only interested in their own monetary earnings. High effort will always be chosen when contracts are complete and low effort when they are incomplete, independent of whether the trade is made in the market or through bilateral negotiations. Therefore, $w_{D A}, w_{B N} \in[20,50]$ with complete contracts and $w_{D A}, w_{B N} \in[0,10]$ for incomplete contracts. Where in these intervals wages will be depends on the direction of market imbalance in the market as a whole. For the finitely repeated game, the assumption of common knowledge of selfinterested players together with the usual backward induction arguments imply that the one-shot prediction is expected in every round. More specifically, considering only wages at integer values and assuming that participants will not engage in contracts at boundary wages (which yield zero profit to one of the partners) for our parameters the effort and wage predictions for any round are those given in table 2 in the main text. ${ }^{1}$ These predictions yield the null hypotheses $\left(\mathrm{H}_{0}\right)$ presented in section 3.

\section{B2. Inequity-aversion}

Next, assume that (some) participants are inequity-averse in the sense of Fehr-Schmidt (1999) (FS99). This model has been successful in explaining a good number of experimental results. ${ }^{2}$ For our parameters, the model gives the utilities $U$ attributed to wage $w\left(\in\left\{w_{D A}, w_{B N}\right\}\right)$ :

$$
\begin{aligned}
& U_{i}(w)=50-w-\alpha_{i} \max \{2 w-70,0\}-\beta_{i} \max \{70-2 w, 0\}, i \in F, \text { high effort } \\
& U_{j}(w)=w-20-\alpha_{j} \max \{70-2 w, 0\}-\beta_{j} \max \{2 w-70,0\}, j \in L, \text { high effort } \\
& U_{i}(w)=10-w-\alpha_{i} \max \{2 w-10,0\}-\beta_{i} \max \{10-2 w, 0\}, i \in F, \text { low effort } \\
& U_{j}(w)=w-\alpha_{j} \max \{10-2 w, 0\}-\beta_{j} \max \{2 w-10,0\}, j \in L, \text { low effort, }
\end{aligned}
$$

where $\alpha_{i}>\beta_{i}>0 \wedge \beta_{i}<1, \forall i \in F$, and $\alpha_{j}>\beta_{j}>0 \wedge \beta_{j}<1 \forall j \in L$. $F(L)$ denotes the set of firms (workers). The terms weighted with $\alpha$ measure disutility attributed to disadvantageous inequity and the terms weighted with $\beta$ measure disutility caused by advantageous inequity. Note that the term $2 w-70$ measures the difference between a worker's earnings ( $w$-20) and a firm's earnings (50-w), while 70$2 w$ measures the reverse.

The most commonly used distribution of $\alpha_{j}$ and $\beta_{j}$ is estimated by FS99 and stems from the accumulated evidence on the ultimatum game (their table III). In their estimates, $\alpha_{j}$ takes on values 0 , $0.5,1$, or 4 (with respective probabilities $0.3,0.3,0.3$ and 0.1 ) and $\beta_{j}\left(<\alpha_{j}\right)$ is equal to $0,0.25$ or 0.6 with probabilities $0.3,0.3$ and 0.4 , respectively. Together, these probabilities imply that $\left(\alpha_{j}, \beta_{j}\right)$ takes on the values $(0,0),(0.5,0.25),(1,0.6)$, or $(4,0.6)$, with probabilities $0.3,0.3,0.3$ and 0.1 , respectively. We use these estimates for deriving hypotheses for the case with incomplete contracts. ${ }^{3}$

\section{B2.1. Complete Contracts}

We first consider complete contracts and once again start with the one shot case. This case is relatively simple since rational firms will fix effort at the high level $(e=1)$. The prediction of FS99 is that competition in DA will crowd out inequity concerns and that wages will be those in the first DA column of table $2 .{ }^{4}$ In $\mathrm{BN}$, inequity-aversion may affect realized wages, since the firm and the worker may view their trading partner as the only relevant reference agent (cf. section 3). However, market imbalance will limit the extent of redistribution. In particular, the short side of the market will not end up with less than half of the surplus from trade (because disadvantageous inequity is considered to be

\footnotetext{
${ }^{1}$ Typically, experimental results for the type of 'Box Design' applied here are not as extreme as the theoretical predictions. With repetition, prices do converge to these predictions, however ( $c f$. Davis and Holt, 1993).

${ }^{2}$ See the discussions in FS99 and Brown et al.(2004). Neugebauer et al. (2008) present an example where the model predicts less well than in most environments.

${ }^{3}$ For obvious reasons, we prefer to use these out-of-sample estimates for the distribution to estimates based on our own data, when deriving predictions for our experiments.

${ }^{4}$ The model by Bolton and Ockenfels (2000) yields a similar prediction. It is consistent with what we know about behavior in double auctions with the so-called box design, as reported in Davis and Holt (1993). Roth et al. (1991) find similar results in Bertrand-type auctions.
} 
more severe than advantageous inequity), though inequity-aversion may preclude it from receiving the entire surplus.

Consider the complete contract case of $\mathrm{BN}$ with excess demand. Because a wage of 35 splits the high surplus equally, the reasoning above implies that wages will lie in the interval $[35,49)$. For these wages, inequity is advantageous to the worker and disadvantageous to the firm. The linearity of utility in inequity implies that for workers with $\beta_{j}>0.5-$ a high aversion of being ahead - utility is decreasing in the wage, so that they will accept an offer of $w_{B N}=35$. All other workers will only accept $w_{B N}=49$. Firms' utility is decreasing in $w_{B N}$, independent of $\alpha_{i}$. Hence this linear utility predicts wages $w_{B N} \in\{35,49\} .^{5}$ If we allow for some concavity of the utility function in the extent of inequityaversion, wages in the interior of $[35,49]$ will also be equilibrium wages. ${ }^{6}$ A similar reasoning gives the prediction that $\mathrm{BN}$ wages will be in the interval [21,35] in case of excess demand. These predictions are summarized in table 3 (main text). Once again, the usual arguments suffice to see that these predictions hold for every round of the repeated game (in particular, note that there is no reason for workers to build a reputation of inequity-aversion; nor is there any way for them to do so).

\section{B2.2. Incomplete Contracts}

For two reasons, the case with incomplete contracts may be more complicated than the cases discussed above. First, inequity-averse workers may choose their effort level differently than inequityneutral workers and this may affect the firm's wage offer, even in the one shot version of the game. Second, in early rounds inequity-neutral workers may act like their inequity-averse colleagues in an attempt to build a reputation from which they can benefit in later rounds.

Using backward induction, we proceed as follows: (i) we ask how effort (now chosen by the worker) depends on the worker's inequity-aversion and the wage; (ii) we determine the expected utility for firms as a function of the wage. Aside from her own inequity-aversion, this depends on the expectations the firm has about the worker choosing high effort, i.e., on the expected inequityaversion of the worker; (iii) this will typically yield ranges of wages with positive expected utility for both firm and worker. Market imbalance will select wages from these ranges that favor the short side of the market as predictions. For example, if wages in the range $[\mathrm{X}, \mathrm{Y}]$ yield positive expected utility for the firm and there is excess demand, then competition among the firms will drive wages up to Y; (iv) finally, we will assemble the pieces of the puzzle and consider behavior across rounds, where workers' decisions may be influenced by the reputation they yield for future encounters.

\section{Workers' effort choice in the one shot environment}

We start with the relationship between effort and wage. There are three distinct intervals of wages $w \in\left\{w_{B N}, w_{D A}\right\}$ for which the effort choice differs (cf. SBG).

1) Low wages $w \in[0,5]$ will always yield low effort, since such wages give to the worker less than $50 \%$ of the surplus generated by low effort and no level of inequity-aversion can induce a worker to exert high effort.

2) For $w \in[35,50]$ workers obtain at least $50 \%$ of the surplus for high effort, so that they will always earn more than the firm (of course the difference is larger if they choose low effort than for high effort). Straightforward calculations (see SBG) show that for these wages workers will exert high effort if and only if $\beta_{j} \geq 0.33$, i.e. if they sufficiently dislike coming out ahead.

3) When $w \in(5,35)$, workers have a reservation wage $w^{r}\left(\alpha_{j}, \beta_{j}\right)$ and they will exert high effort if and only if $\beta_{j} \geq 0.33$ and $w \geq w^{r}\left(\alpha_{j}, \beta_{j}\right) .^{7}$ In other words, workers have to be sufficiently averse to advantageous inequity (not to exploit the firm by choosing low effort) and the wage must exceed a threshold that is determined by the worker's inequity-aversion (to accept getting the smaller part of the high surplus).

As a consequence, workers with $\beta_{j} \leq 0.33$ will never exert high effort. For the FS estimates presented above only the $40 \%$ of the workers (those with $\left(\alpha_{j}, \beta_{j}\right)=(1,0.6)$ or $\left.\left(\alpha_{j}, \beta_{j}\right)=(4,0.6)\right)$ may do so. For these parameters, we obtain the reservation wages $w^{r}(1,0.6)=30$ and $w^{r}(4,0.6)=33.26$ (cf. eq. 5 in

\footnotetext{
5 If workers' inequity-aversion is distributed as in the FS99 estimates, the average observed wage will be $0.4 * 35+0.6 * 49=43.4$.

${ }^{6}$ Throughout the analysis we will assume that such non-lienearities are possible. Similarly, FS99 explain offers in dictator games by dropping the linearity assumption.

${ }^{7}$ For simplicity, we assume in our discussion that workers will exert high effort if they are indifferent.
} 
SBG). Therefore workers with $\alpha_{j}=1$ and $\beta_{j}=0.6$ (30\% in FS99) will exert high effort for any $w \in[30$, 50] and those with $\alpha_{j}=4$ and $\beta_{j}=0.6(10 \%)$ will give high effort for any $w \in[34,50]$.

\section{Firms' wage offers in the one shot environment}

Given these effort choices, we can determine the implications for firms of engaging in contracts at various wages. Distinguishing between the same three wage intervals, we focus on the wages that lead to positive expected utility. These are the wages that are preferred to not trading at all. ${ }^{8}$

1) For any $w \in[0,5]$ a firm knows that it will obtain a profit $\pi_{f}=10-w$ and the worker will earn $\pi_{l}=w$; inequity is advantageous to the firm $\left(\pi_{f}>\pi_{l}\right)$. Hence, the firm's disadvantageous inequityaversion, $\alpha_{i}$, is irrelevant. In SBG we show that for any value of advantageous-inequity-aversion, $\beta_{i}$, the firm will obtain for any wage in this interval a positive level of utility. As a consequence, firms are always willing to engage in contracts with $w \in[0,5]$.

2) For $w \in[35,50]$ to yield positive expected utility a firm must

(i) care sufficiently little about the disadvantageous inequity that results from these wages, i.c., $\alpha_{i}<0.25$ (eq. 13 in SBG; this only holds for the $30 \%$ with $\alpha_{I}=0$ in the FS99 estimates); and

(ii) believe that a sufficient number of workers will respond with high effort i.c., $p_{., 0.6}>0.625$; (eq. 11 in SBG); where $p_{., 0.6}$ denotes the probability that the trading partner has $\beta_{j} \geq 0.33$ (which holds for $40 \%$ of the workers in the FS99 estimates).

3) For $w \in(5,35)$, the firm forms beliefs about the distribution of reservation wages. For the FS99 estimates, the relevant reservation wages are $w^{r}(1,0.6)=30$ and $w^{r}(4,0.6)=33.26$. Hence, for wages $30,31,32$ and 33 it matters how the firm estimates the probability that $\left(\alpha_{j}, \beta_{j}\right)=(1,0.6)$, which we denote by $p_{1,0.6}$. For $w=34$, workers with $\left(\alpha_{j}, \beta_{j}\right)=(4,0.6)$ will also choose high effort and the probability $p_{., 0.6}=p_{1,0.6}+p_{4,0.6}$ needs to be high enough. Recall that for these wages $(<35)$ inequity is (dis)advantageous to the firm if the worker chooses high (low) effort. The firm's expected utility for contract wage $w$ is then given by ( $c f$. eq. 17 in SBG):

$$
E U_{i}(w)=\operatorname{Pr}(w) \bullet\left(50-w-\beta_{i}(70-2 w)\right)+(1-\operatorname{Pr}(w)) \bullet\left(10-w-\alpha_{i}(2 w-10)\right),
$$

where $\operatorname{Pr}(\mathrm{w})=0$ for $\mathrm{w} \in\{5,6, . ., 29\}, \operatorname{Pr}(\mathrm{w})=p_{1,0.6}$, if $w \in\{30,31,32,33\}$, and $\operatorname{Pr}(\mathrm{w})=p_{., 0.6}$ if $w=34$. Some straightforward manipulations then show that $E U_{i}(w)>0$ iff:

$$
\operatorname{Pr}(w)>\frac{\left(1+2 \alpha_{i}\right) w-10\left(1+\alpha_{i}\right)}{40-70 \beta_{i}-10 \alpha_{i}+2 w\left(\alpha_{i}+\beta_{i}\right)} .
$$

Table B1: Firms and Positive Expected Utility

\begin{tabular}{|l|c|c|c|c|}
\hline wage & $\begin{array}{l}\alpha_{\mathrm{i}}=0 \\
\beta_{\mathrm{i}}=0\end{array}$ & $\begin{array}{c}\alpha_{\mathrm{i}}=0.5 \\
\beta_{\mathrm{i}}=0.25\end{array}$ & $\begin{array}{c}\alpha_{\mathrm{i}}=1 \\
\beta_{\mathrm{i}}=0.6\end{array}$ & $\alpha_{\mathrm{i}}=4 \beta_{\mathrm{i}}=0.6$ \\
\hline$\in[0,10]$ & \multicolumn{4}{|c|}{ All wages yield positive expected utility } \\
\hline$\in[11,29]$ & \multicolumn{4}{|c|}{ All wages yield negative expected utility } \\
\hline $30\left(\mathrm{p}_{1,0.6}>\right)$ & 0.500 & 0.720 & 0.833 & 0.940 \\
\hline $31\left(\mathrm{p}_{1,0.6}>\right)$ & 0.525 & 0.734 & 0.837 & 0.941 \\
\hline $32\left(\mathrm{p}_{1,0.6}>\right)$ & 0.550 & 0.748 & 0.841 & 0.943 \\
\hline $33\left(\mathrm{p}_{1,0.6}>\right)$ & 0.575 & 0.761 & 0.844 & 0.944 \\
\hline $34\left(\mathrm{p}_{\cdot, 0.6}>\right)$ & 0.600 & \multicolumn{4}{|c|}{0.774} & 0.847 & 0.945 \\
\hline$\in[35,50]\left(\mathrm{p}_{\cdot, 0.6}>\right)$ & 0.625 & All wages yield negative expected utility* \\
\hline
\end{tabular}

Notes: Columns refer to inequity-aversion of the firm. Numbers indicate thresholds for the beliefs about workers' inequity-aversion. For example, if a inequity-neutral firm (second column) believes that the probability that the partner has $\alpha_{j}=1$ and $\beta_{j}=0.6\left(\mathrm{p}_{1,0.6}\right)$ is equal to 0.54 and the probability that $\alpha_{j}=4$ and $\beta_{j}=0.6$ is equal to 0.1 (hence, $\mathrm{p}_{., 0.6}=0.54+0.1=0.64$ ), than wages 30,31 , and 35 or higher will all yield positive expected utility. Finally, for any wage larger than 10 , workers with $\beta_{j}=0.6$ will choose high effort and those with $\beta_{j}=0$ or $\beta_{j}=0.25$ will choose low effort.

*Because $\alpha_{i}>0.25$ in all of these cases.

\footnotetext{
${ }^{8}$ Throughout the analysis, we assume that firms are risk-neutral. Risk aversion (seeking) would decrease (expand) the set of acceptable wages, without affecting our comparative static predictions.
} 
Recall that the inequity parameters $\alpha_{i}$ and $\beta_{i}$ refer to the firm's inequity-aversion. The (expected) inequity-aversion of workers is captured in $\operatorname{Pr}(w)$. For the inequity-aversion parameters of FS99, table B1 shows the beliefs that are necessary to make the wages depicted in column 1 yield positive expected utility for the firm.

The table shows, for example, that for inequity-averse firms with $\beta_{\mathrm{I}}=0.6$ and $\alpha_{i} \geq 1$, only extreme beliefs $\left(p_{1,0.6}>0.83\right)$ about the inequity-aversion of the workers will make firms consider any wages higher than 10 to be beneficial. Therefore, more inequity-aversion by firms decreases the probability of high wages being observed. Recall that FS99 estimate $p_{., 0.6}=0.4$ and $p_{1,0.6}=0.3$. As a consequence, if firms believe that workers' inequity-aversion is distributed as estimated by FS99, they will not engage in any contracts where the wage exceeds 10.

If wages are observed in this intermediate range, the firms concerned are most likely to be inequity-neutral. The intuition is that the fear of a disadvantageous low effort choice dominates the decision of inequity-averse firms because disadvantageous inequity weighs more heavily than advantageous inequity. Hence inequity-averse firms would have to be very convinced that workers will choose high efforts for them to take the risk of engaging in a high wage contract.

A first conclusion from this analysis is more basic, however: with incomplete contracts low effort and low wages will (at least) sometimes be observed, whereas they are never observed in case of complete contracts.

\section{Behavior across rounds}

If the game is played only once and firms believe that workers' inequity-aversion is distributed according to the FS99 estimates, firms will offer low wages and workers will give low effort. In the (finitely repeated) game, inequity-averse workers have a chance to obtain a reputation of giving high effort that allows firms to update their beliefs sufficiently to offer high wages. As a consequence, firms may sufficiently update their beliefs about a worker they are negotiating with in BN (based on this worker's past choices) to offer high wages. This process will not occur in DA, where no information is given. A formal analysis requires a more thorough investigation of possible equilibria, however. In doing so, we distinguish between 'pooling' equilibria and 'separating' equilibria.

\section{Behavior across rounds: pooling equilibrium with low effort}

One simple equilibrium is where all firms offer low wages and all workers choose low effort, in both DA and BN. Firms have no reason to update their prior belief that there is only a $40 \%$ chance that a worker is (sufficiently) inequity-averse and act optimally according to this belief. Workers (whether inequity-neutral or inequity-averse) have no incentive to offer high effort.

\section{Behavior across rounds: pooling equilibrium with high effort}

A sequential pooling equilibrium of the Kreps-Wilson (1982) type may exist. ${ }^{9}$ If it does, it will involve firms paying high wages and all workers responding with high effort (in early rounds) in BN. ${ }^{10}$ We will derive conditions for equilibria where firms only offer low wages (and workers respond with low effort) in DA. ${ }^{11}$ Then, in such an equilibrium (if it exists), workers will always accept an offer to enter BN and no trades will take place in DA. We then show that no mutual best responses exist in such a scenario, i.e., unraveling occurs and there is no such pooling equilibrium.

\footnotetext{
${ }^{9}$ Note that there are important differences between our game and the Kreps-Wilson sequential game. These differences include: (i) Information about previous choices is not complete in our experiments. In particular, when firms observe the worker's previous record, they do not know for which wage offers the effort levels were chosen. (ii) Because information is not given in the DA, it is not clear what probabilities firms will attribute to the worker being inequity-averse (enough). (iii) Information about previous choices is also not complete because firms do not know whether a previous effort choice by the worker was made after a trade in the market or after a bilateral trade. (iv) Information about previous choices is only given in BN. Because of market imbalance, some workers or firms will be excluded from these negotiations. (v) There is two-sided imperfect information in this game, because firms are characterized by their inequity-aversion as well. Though Kreps and Wilson (1982) discuss an example of two-sided imperfect information, their case does not apply here. In particular, one of their players (the entrant) reveals its type (by not entering) for some actions. This does not hold in our case: irrespective of $\alpha_{i}$ and $\beta_{i}$, there are beliefs for which firms rationally choose low or high wages.

${ }^{10}$ Because actions of distinct worker types differ in late rounds, the equilibria we are investigating are not really 'pooling' equilibria. We use this term to ease the discussion.

${ }^{11}$ Note that the only way for firms to distinguish between both types of workers is by selection based on past worker behavior. Because no information is provided in DA, a rational firm will not offer high wages there.
} 
To simplify the analysis we only consider the probability $p_{., 0.6}$, i.e., the probability that the worker's inequity-aversion is characterized by $\beta_{j}>0.33$ (which is a sufficient but not necessary condition for a high wage offer to yield positive expected utility to the firm). Let there be $\mathrm{N}$ rounds, and let $\mathrm{n} \leq \mathrm{N}$ denote the current round, counting backwards from the start. In our experiments, $\mathrm{N}=20$. Denote by $p_{n}$ the firm's belief about $p_{., 0.6}$ in round $\mathrm{n}$ (as in Kreps and Wilson 1982, $p_{n}$ is a sufficient statistic for the history of play to period $n$ ). The FS99 estimates imply $p_{N}=0.4$. Because inequityaverse workers (with $\beta_{j}>0.33$ ) will choose high effort after high wage and wages will be high in a pooling equilibrium, an off-equilibrium choice of low effort in round $n\left(e_{n}=0\right)$ suffices to set $p_{t}=0, t=n$ $1, \ldots, 1$. Moreover, any refusal to enter $\mathrm{BN}$ or any rejection to a high wage offer in $\mathrm{BN}$ will make the firm offer a low wage on BN in future rounds. Finally, let $q_{n}$ denote the probability that a worker with $\beta_{j}<0.33$ will exert high effort. The pooling equilibrium we are considering involves $q_{n}=1$, for $\mathrm{n} \in\left\{\mathrm{n}^{*}, \ldots, \mathrm{N}\right\}, 1<\mathrm{n}^{*} \leq \mathrm{N}$. For a firm, the probability that the worker will respond to $w$ with high effort in round $n$ is now $\bar{P}_{n}=p_{n}+\left(1-p_{n}\right)^{*} q_{n}$. Wage $w_{B N}$ will yield positive expected utility to the firm if $P_{n}$ satisfies the condition in the relevant column of table B1.

Excess supply of labor

First consider the case of excess supply of labor (i.e., 5 workers and 2 firms). Note that in this case the larger part of any surplus will go to the firm. Given the reservation wages of inequity-averse workers, $w_{B N} \in[30,35]$ if $P^{n}$ is large enough, and $w_{B N} \in[1,5]$, otherwise. If the worker is inequity-neutral (the case we are interested because we are studying reputation building), the firm's inequity-aversion determines which wage in these intervals will be realized, with the relative position being the same in the two intervals. We simplify the analysis and assume that $w_{B N}=30$ or $w_{B N}=1 .{ }^{12}$

First, assume that firms offer $w_{B N}=30$ to any worker who has a history of only high effort choices, $w_{B N}=1$ if the worker ever chose low effort and $w_{D A}=1$. Consider a inequity-neutral worker being offered $w_{B N}=30$ in round $n$. Let $\pi_{n}^{*}$ denote the expected earnings this worker will make if she chooses the effort level $e_{n}^{*}$ that maximizes expected earnings in the remainder of the game, conditional on the firm using the strategy described. Obviously, for the final round this means $e_{1}^{*}=0$ and $\pi_{1}^{*}=30$. In the penultimate round, low effort yields 30 immediately and $w_{B N}=1$ in the final round, if she is selected to negotiate (which occurs with probability 0.4 due to excess supply). Hence, her expected earnings from low effort in $n=2$ are $30+0.4 * 1=30.4$. If she chooses high effort in the penultimate round, she will have immediate earnings of 10 and there is a $40 \%$ chance that she will be selected in $n=1$, in which case she will be able to obtain $\pi_{1}^{*}=30$. Hence, her expected earnings from high effort in $n=2$ are $10+0.4 * 30=22$. As a consequence, $e_{2}^{*}=0$ and $\pi_{2}^{*}=30.4$. Now, consider her decision in round $n>2$. If she chooses low effort, she earns an immediate 30 followed by n-1 times 1 , each time with probability 0.4 ; expected earnings are $30+0.4^{*}(n-1)$. High effort gives an immediate $10, \pi_{n-1}^{*}$ with probability $0.4, \pi_{n-2}^{*}$ with probability $0.6 * 0.4$, etc., yielding expected payoff $10+0.4 \sum_{i=1}^{n-1} 0.6^{n-1-i} * \pi_{i}^{*}$. Solving this recursively yields the result that high effort is the optimal choice for $n \geq 4$ and low effort for $n=1,2,3$. Hence, given the firms' 'grim trigger' strategies, inequityneutral workers best response to high wages is to give high effort in the first 17 rounds of our experiment; i.e., $q_{n}=0, n \in\{1,2,3\}, q_{n}=1, n \in\{4, \ldots, 20\}$. Of course, inequity-averse workers will respond to $w_{B N}=30$ with high effort in every round. In addition, all workers will always accept offers to negotiate in $\mathrm{BN}$.

Such a pooling equilibrium only exists if the firms' best response to the workers' strategies is indeed to reward good reputations in the way described. In particular, the strategies should not unravel in the sense that firms stop offering high wages after round 17 (in which case inequity-neutral workers would resort to low effort in round 16, etc.). Unraveling will take place unless rents exist after round 17 that make it worthwhile to the firm to reward good reputations. E.g., in Brown et al. 2004, there

\footnotetext{
${ }^{12}$ The analysis can easily be repeated for other wages, which yields almost identical results.
} 
are assumed to be enough inequity-averse workers to give firms a positive expected benefit from a high wage offer. In our case, for $n \in\{4, \ldots, 20\}, P_{n}=1$, which exceeds every value in table B1, so all firms will offer $w_{B N}=30$. Because no information is available from rounds 1 to 17 to distinguish between inequity-averse and inequity-neutral workers, rational firms will rely on their priors in round $18(n=3): P_{3}=p_{3}=p_{20}=0.4$. Hence, the expected direct return to a high wage offer is $0.4 *(50-30)+$ $0.6 *(10-30)=-4$. This is lower than the expected direct return to a low wage offer (which is 10-1=9). However, there are positive spillover effects of a high wage offer in round $18(n=3)$ to rounds 19 and 20 because those inequity-neutral workers who are selected (and choose low effort) in round 19 will be recognized as such in subsequent rounds. Simple calculations show that these positive effects are not large enough to increase total benefits from a high wage offer in round 18 beyond the benefits of a low offer. Ergo, firms will offer low wages to all workers in round 18 and reputation building unravels: no pooling equilibrium exists. ${ }^{13}$

Excess demand for labor

Unraveling is easier to show with excess demand (2 workers, 5 firms), where the larger part of any surplus will go to the worker: $w_{B N} \in[35,49]$ if $P^{n}$ is large enough, and $w_{B N} \in[5,9]$, otherwise. Because we again focus on inequity-neutral workers (to determine $q_{n}$ ) we assume that $w_{B N}=49$ or $w_{B N}=9$ and consider the scenario where firms offer $w_{B N}=49$ to any worker who has a history of only high effort, $w_{B N}=9$ if the worker ever chose low effort and $w_{D A}=9$.

Consider a inequity-neutral worker being offered $w_{B N}=49$ in round $n$. We again proceed by determining $\pi_{n}^{*}$. It is easy to see that $\pi_{1}^{*}=49$. For $n=2$, the worker can either choose high effort (yielding 29+49 in the last round) or low effort (yielding 49+9). Hence, $\pi_{2}^{*}=78$. Thus, given the firms' strategy, the worker will offer high effort in rounds 1-19 and low effort in the final round. Obviously, the firms' strategy is not an optimal response to this and reputation building unravels. Once again, no pooling equilibrium exists.

\section{Behavior across rounds: separating equilibrium}

Finally, we consider the possibility of a separating equilibrium where inequity-averse workers choose high effort and inequity-neutral workers choose low effort. For such an equilibrium to exist, it must be possible for firms to distinguish between the two. In particular, inequity-neutral workers should not be able to choose high effort in a subset of rounds in an attempt to be treated as inequity-averse workers. The existence of DA complicates matters in this respect. In DA, firms have no information about the worker's past and cannot condition their choice. Therefore, the most likely candidate for a separating equilibrium is one where wage offers are low in DA. Once again, we consider grim-trigger strategies for the firm, where any low effort choice by the worker in the past is answered by low wage offers only. As a consequence, inequity-averse workers will not engage in any transactions in DA.

Now, assume that a separating equilibrium exists, i.e., inequity-neutral workers trade in DA and $\mathrm{BN}$ and receive low wage offers, to which they respond with low effort. Inequity-averse workers only trade in BN, offer high effort the first time they receive a (low) wage offer and always choose high effort after that. Firms start by offering low wage. If they observe (only) high effort choices, they offer the worker a high wage. It is easy to see that this cannot be an equilibrium. A inequity-neutral worker can offer high effort the first time she is selected for BN. This gives a direct loss of 20 (the costs of high effort) but the possibility to gain 30 (with excess supply) or 49 (excess demand) the next time she is selected. Hence, no such separating equilibrium exists.

\footnotetext{
${ }^{13}$ Similar results are obtained assuming a more forgiving strategy for the firms than the grim trigger assumed here. The bottom line is that inequity-neutral workers will at some point switch to low effort and the firm cannot obtain sufficient rents in the rounds after that to make it optimal for them to stick to their strategy. Again, unraveling occurs. Moreover, the unraveling is quite robust to the assumptions made about the distribution of inequity aversion. Even if we reverse the probabilities and assume that $60 \%$ of the workers are inequity averse $\left(p_{N}=0.6\right)$, no pooling equilibrium with high effort exists.
} 